\title{
Comprehensive gene and pathway analysis of cervical cancer progression
}

\author{
YUEXIONG YI* ${ }^{*}$ YAN FANG* ${ }^{*}$ KEJIA WU, YANYAN LIU and WEI ZHANG \\ Department of Obstetrics and Gynecology, Zhongnan Hospital of Wuhan University, Wuhan, Hubei 430071, P.R. China
}

Received June 24, 2019; Accepted January 15, 2020

DOI: $10.3892 / 01.2020 .11439$

\begin{abstract}
Cervical Cancer is one of the leading causes of cancer-associated mortality in women. The present study aimed to identify key genes and pathways involved in cervical cancer (CC) progression, via a comprehensive bioinformatics analysis. The GSE63514 dataset from the Gene Expression Omnibus database was analyzed for hub genes and cancer progression was divided into four phases (phases I-IV). Pathway enrichment, protein-protein interaction (PPI) and pathway crosstalk analyses were performed, to identify key genes and pathways using a criterion nodal degree $\geq 5$. Gene pathway analysis was determined by mapping the key genes into the key pathways. Co-expression between key genes and their effect on overall survival (OS) time was assessed using The Cancer Genome Atlas database. A total of 3,446 differentially expressed genes with 107 hub genes were identified within the four phases. A total of 14 key genes with 11 key pathways were obtained, following extraction of $\geq 5$ degree nodes from the PPI and pathway crosstalk networks. Gene pathway analysis revealed that $C D K 1$ and $C C N B 1$ regulated the cell cycle and were activated in phase I. Notably, the following terms, 'pathways in cancer', 'focal adhesion' and the 'PI3K-Akt signaling pathway' ranked the highest in phases II-IV. Furthermore, FNI, ITGBI and $M M P 9$ may be associated with metastasis of tumor cells. $S T A T 1$ was indicated to predominantly function at the phase IV
\end{abstract}

Correspondence to: Professor Wei Zhang, Department of Obstetrics and Gynecology, Zhongnan Hospital of Wuhan University, 169 Donghu Road, Wuhan, Hubei 430071, P.R. China E-mail: zw6676@163.com

*Contributed equally

Abbreviations: CC, cervical cancer; CIN, cervical intraepithelial neoplasia; GO, Gene Ontology; PPI, protein-protein interaction; TCGA, The Cancer Genome Atlas; DEG, differentially expressed gene; OS, overall survival; STRING, Search Tool for the Retrieval of Interacting Genes; KEGG, Kyoto Encyclopedia of Genes and Genomes; JC, jaccard coefficient; OC, overlap coefficient; PINA, protein interaction network analysis

Key words: cervical cancer, bioinformatics analysis, diagnosis, progression via cancer-associated signaling pathways, including 'pathways in cancer' and 'Toll-like receptor signaling pathway'. Survival analysis revealed that high $I T G B 1$ and $F N 1$ expression levels resulted in significantly worse OS. $C D K 1$ and $C C N B 1$ were revealed to regulate proliferation and differentiation through the cell cycle and viral tumorigenesis, while FNI and ITGBI, which may be developed as novel prognostic factors, were co-expressed to induce metastasis via cancer-associated signaling pathways, including PI3K-Art signaling pathway, and focal adhesion in $\mathrm{CC}$; however, the underlying molecular mechanisms require further research.

\section{Introduction}

Cervical Cancer (CC) is a highly aggressive tumor and is one of the leading causes of cancer-associated mortality in women, with an estimated 570,000 new cases and 311,000 deaths in 2018 worldwide (1). Women with CC are considered to have a lower quality of life (2). The progression of CC, from normal cervical mucosal epithelium to cervical intraepithelial neoplasia (CIN) grade 1,2 , and 3 , to CC (3) is associated with persistent high-risk human papillomavirus (HPV) infection (4). Furthermore, a number of risk factors, including early sexual activity (5), multiple sexual partners (6), long-term use of oral contraceptives (7), genetic factors [active oncogenes, including PIK3CA (8), ATAD2 (9) and CRNDE (10); tumor suppressor genes, including p53 (11), Ras association domain family 1 isoform A (12) and NOL7 (13)], tobacco use [current smoker, started smoking age $\leq 15$ years, smoking duration $\geq 30$ years, $\geq 20$ cigarettes/day (14)] and other viral infections (such as HIV, herpes simplex virus (HSV) type II and bacterial infections caused by Chlamydia trachomatis) (15) have been associated with CC progression.

HPV infection plays a leading role in CC (16). The DNA of HPV integrates into the host cell genome [HPV16: q21-q31 of chromosome no. 13; HPV18: q24 of chromosome no. 8 (17)], disrupts the open reading frame and causes overexpression of E6 and E7 genes (18). It has been verified that E6 and E7 exert carcinogenic effects by binding to the cell cycle regulators, p53 and retinoblastoma (Rb) (19). While E6 and E7 proteins are upregulated, E6 can interact with its associated protein [E6-associated protein, E6AP (20)] to form a complex and bind to $\mathrm{p} 53$. This binding hydrolyzes p53 and results in the loss of p53-induced negative regulation of cell proliferation, thereby leading to unchecked cellular proliferation and 
malignant transformation (21). E7 has a high affinity for $\mathrm{Rb}$, which controls the cell cycle. Binding of E7 to Rb can dissociate the Rb-E2F complex, thus releasing E2F to exert its role as a transcription factor, which leads to an uncontrolled cell cycle and cellular immortalization $(22,23)$. Furthermore, centrosomes are central regulators of mitosis that are often increased in numbers in cancer cells (24). A previous study indicated that an abnormally increased number of centrosomes is associated with structural chromosomal abnormality in cervical lesions with high risk of HPV infection (25). Duensing and Münger (26) reported that abnormal number of centrosomes and associated spindle mitotic abnormality can be found in cells infected by the high-risk HPV16 E6 and E7 proteins, but not in cells infected by the low-risk HPV6. Although numerous experimental studies on genes [HPV16 L1 protein (27), sonic hedgehog (28) and FGFR4 (29)], and signaling pathways [Wnt/ $\beta$-catenin signaling pathway (30), adenosinergic pathway (31) and ERK signal transduction (32)], as well as bioinformatics analyses have focused on microRNAs (33) and genes (34) associated with CC, and have provided an understanding of the pathophysiological mechanisms of the disease over the last decade, the underlying molecular mechanisms remain unclear.

The development of CC occurs over a number of years and its complexity presents clinical challenges in patients screening and treatment. Currently, The Bethesda System (35), which is a tool that is used to report Pap smear results for cervical cytologic diagnoses, provides useful data that allows research into the epidemiology, biology and pathology of cervical lesions; however, its diagnostic value remains poor (36). Instead, direct biopsy remains the gold standard for diagnosis. Nevertheless, invasive examinations may cause adverse psychological effects, including anxiety, depression or distress (37). Surgery, chemotherapy and radiotherapy (38) are the three major therapeutic strategies in the treatment of CC; however, their uses may be limited for various reasons. Surgery may be limited by the status and stage of patients, including late stage or tolerance to anesthesia (39), whereas chemotherapy is limited due to the lack of sensitivity and the development of drug resistance (40). In addition, radiotherapy can be limited by the maximum tolerated dose to adjacent normal tissues (41). Thus, it is essential to understand the underlying molecular mechanisms in the initiation and development of $\mathrm{CC}$, in order to develop methods for its accurate diagnosis and effective treatment. A number of studies have reported that multiple genes [CXCL12 (42), FGFR4 (29) and SHH (43)], proteins [cyclin D1 (44), FOXO1 (45) and BASP1 (46)] and pathways [Toll-like signaling pathway (47), VEGF signaling pathway (48) and Wnt signaling pathway (30)] are involved in the natural progression of CC; however, few studies have investigated the fundamental pathological molecular mechanisms in the progression of CC (from normal, to CIN1, CIN2, CIN3, to cancer). Thus, the specific pathological processes remain unclear.

The present study provided a systematic investigation of the development of $\mathrm{CC}$ and further understanding of the associations between the four phases of CC progression, and thus revealed additional targets for the detection and treatment of CC. A flow diagram of the present study is presented in Fig. 1.

\section{Materials and methods}

Identification of differentially expressed genes (DEGs). The CC gene expression profile in the GSE63514 dataset, acquired using the GPL570 platform (Affymetrix Human Genome U133 Plus 2.0 Array) provided by den Boon in 2015 (49), was downloaded from the GEO database (https://www.ncbi.nlm. nih.gov/geo/). The profile contained 128 cervical specimens, including: Normal ( $n=24)$, CIN1 $(n=14)$, CIN2 ( $n=22)$, CIN3 $(n=40)$ and cancer $(n=28)$ samples. All samples were divided into four phases as follows: Phase I, normal to CIN1; phase II, CIN1 to CIN2; phase III, CIN2 to CIN3 and phase IV, CIN3 to cancer, and GEO2R tools (https://www.ncbi.nlm. nih.gov/geo/geo2r/) (50) within the limma package version 3.26.8 (51) were used to screen the DEGs at the four phases. The criteria fold change (FC) of expression $>2$ and $\mathrm{P}<0.05$ were used to identify DEGs.

Identification of hub genes. The Search Tool for the Retrieval of Interacting Genes (STRING) database (52) and Cytoscape software (version 3.5.1) (53) were used to identify the hub genes in the four phases. The PPI network was constructed by searching for gene symbols and the minimum required interaction score was set at 0.7 , to ensure high confidence in the results. The nodes that not connect to the major network were removed to decrease the error detection rate. CytoHubba (54), a plug-in for Cytoscape software, was used to investigate notable nodes in the interactome network using 12 topological algorithms, including Degree, Edge Percolated Component, Maximum Neighborhood Component, Density of Maximum Neighborhood Component and Maximal Clique Centrality, and centralities based on shortest paths, such as Bottleneck, EcCentricity, Closeness, Radiality, Betweenness, Clustering Coefficient and Stress. The genes that ranked in the top 10 for each topological algorithm were extracted and the duplication of each gene was calculated. Genes duplicated $<2$ times were excluded, in order to guarantee that the genes were associated with $\mathrm{CC}$. The remaining genes were considered as hub genes in the four phases.

Functional enrichment analyses of $G O$ and pathways. The functional features of the genes associated with the four phases were examined using WebGestalt (55) and ToppGene (56). In WebGestalt, over-representation analysis was selected as the enrichment method, Biological Process in GO as the functional database, gene symbol as the gene ID type and genome as the reference set for enrichment analysis. In ToppGene, two frequently used databases, Kyoto Encyclopedia of Genes and Genomes (KEGG; https://www.kegg.jp/) and BioCarta (https://www.biocarta.com/), were utilized to perform pathway enrichment analysis, to improve the reliability of the results. Pathways with a false discovery rate of $\mathrm{P}<0.05$ were considered to indicate significantly enriched pathways.

Pathway crosstalk analysis. Pathway crosstalk analysis was performed (57), to investigate the interactions among the significantly enriched pathways. The pathways with either a false discovery rate of $\mathrm{P}>0.05$ or $<3$ genes were removed as selection criteria. The number of shared genes between pairwise pathways was calculated and pairwise pathways with $<2$ overlapping genes were removed. The Jaccard Coefficient (JC) 


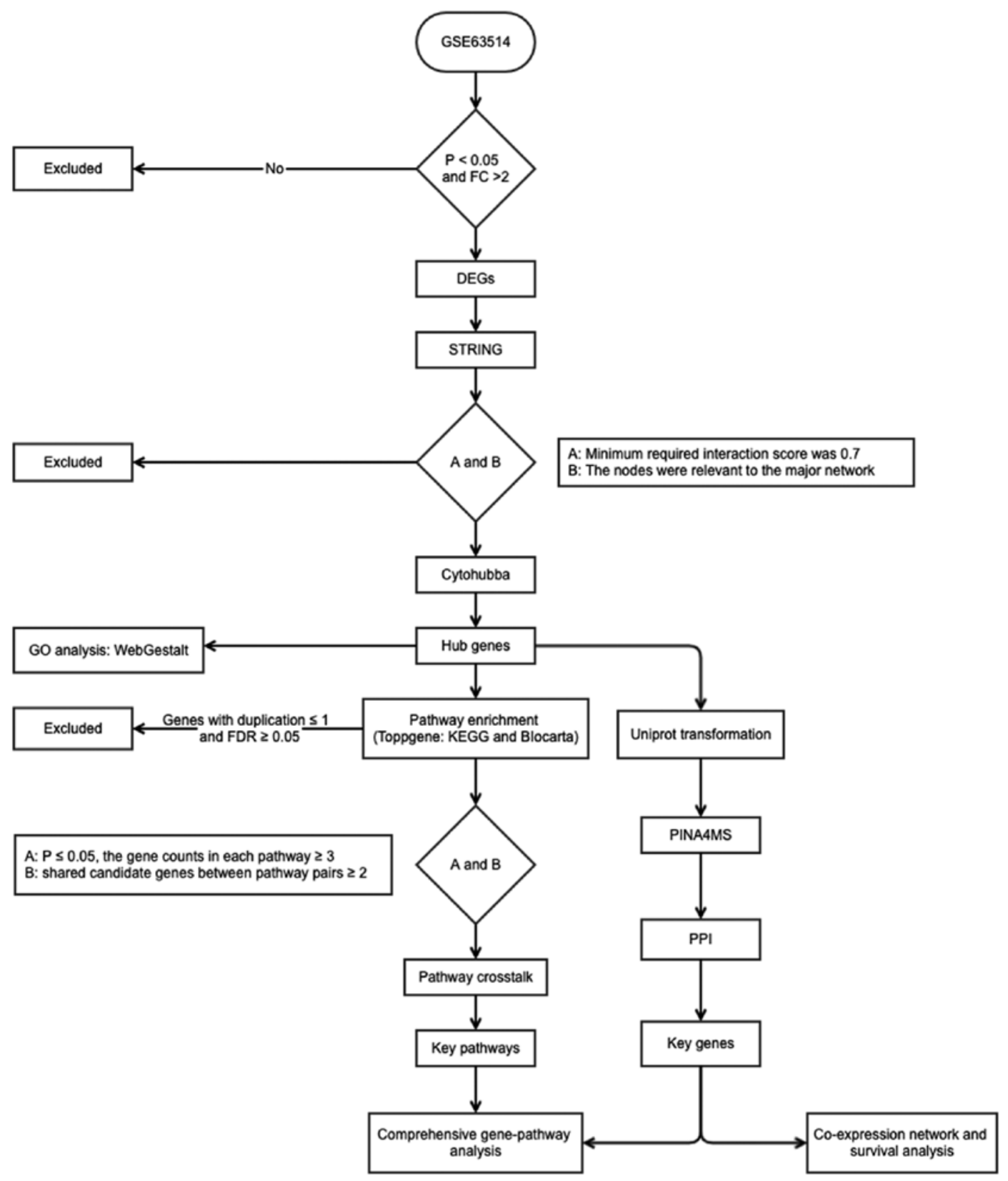

Figure 1. Flow diagram of the present study. FC, fold change; DEGs, differentially expressed genes; STRING, Search Tool for the Retrieval of Interacting Genes/Proteins; GO, Gene Ontology; FDR, false discovery rate; KEGG, Kyto Encyclopedia of Genes and Genomes; PPI, protein-protein interaction.

and the Overlap Coefficient (OC) parameters were calculated, to measure the overlap between the pathways. Specifically, $\mathrm{JC}=\mid \frac{\mathrm{A} \cap \mathrm{B}}{\mathrm{AUB}}$, while $\mathrm{OC}=\frac{\mathrm{|A \cap B} \mid}{\min (\mathrm{A} A \mathrm{BB})}$, where $\mathrm{A}$ and $\mathrm{B}$ represent the gene numbers of the tested pathways. The interrelationships between pathways were visualized using Cytoscape software.

To determine the overall progression and further detect an association between two pathways, the KEGG and BioCarta databases were used to identify the upstream or downstream associations between pathways. Furthermore, the nodal degree was calculated using Centiscape (58) to identify key nodes. According to Han et al (59), key nodes are considered as those with a nodal degree $\geq 5$.

Integration of the PPI network. The PPI network (60) was used to identify key proteins for the four phases of CC. As Protein Interaction Network Analysis (PINA) (https://omics.bjcancer. org/pina/) (61) is an integrated platform for protein interaction network construction, analysis and visualization, it can identify the associations between the queried genes based on integration of data from six public PPI databases: IntAct (62), MINT (63), BioGRID (64), DIP (65), HPRD (66) and MIPS MPact (67). Thus, the PINA4MS plug-in for Cytoscape software was used to construct the PPI network, to identify $\mathrm{CC}$ progression-associated genes. As PINA4MS requires UniProt accession numbers, the UniProt Retrieve/ID mapping tool (https://www.uniprot.org/uploadlists/) was used to input gene symbols. The key nodes for the PPI network were also extracted using a criterion of nodal degree $\geq 5$.

Comprehensive gene-pathway analysis. To determine the molecular mechanisms and associations between the key genes and pathways, the gene-pathway network was constructed by 
Table I. Hub genes in phases I-IV.

\begin{tabular}{|c|c|c|c|c|c|}
\hline Phase & Gene & Regulation & Counts & LogFC & P-value \\
\hline \multirow[t]{29}{*}{ Phase I } & CDK1 & + & 7 & 1.24 & $<0.01$ \\
\hline & KIF11 & + & 7 & 1.27 & 0.01 \\
\hline & BUB1B & + & 6 & 1.13 & 0.02 \\
\hline & BUB1 & + & 5 & 1.17 & 0.01 \\
\hline & CCNA2 & + & 5 & 1.01 & $<0.01$ \\
\hline & HLA-DPA1 & + & 5 & 1.49 & 0.03 \\
\hline & CENPE & + & 5 & 1.36 & 0.02 \\
\hline & RHOA & + & 4 & 1.47 & $<0.01$ \\
\hline & KIF15 & + & 4 & 1.11 & $<0.01$ \\
\hline & CCNB1 & + & 4 & 1.23 & 0.01 \\
\hline & NDC80 & + & 4 & 1.47 & 0.01 \\
\hline & TTK & + & 4 & 1.14 & $<0.01$ \\
\hline & STAT1 & - & 4 & -1.47 & 0.03 \\
\hline & CXCL10 & + & 4 & 2.47 & $<0.01$ \\
\hline & KIF23 & + & 4 & 1.48 & 0.01 \\
\hline & KIF4A & + & 3 & 1.00 & 0.05 \\
\hline & PSMB9 & + & 3 & 1.12 & 0.03 \\
\hline & GNG2 & + & 3 & 1.26 & 0.04 \\
\hline & SPAG5 & + & 2 & 1.15 & 0.01 \\
\hline & TRIP13 & + & 2 & 1.09 & 0.02 \\
\hline & ANLN & + & 2 & 1.19 & 0.02 \\
\hline & CDKN3 & + & 2 & 1.83 & $<0.01$ \\
\hline & KIF14 & + & 2 & 1.15 & 0.01 \\
\hline & MKI67 & + & 2 & 1.45 & 0.01 \\
\hline & NUSAP1 & + & 2 & 1.22 & 0.02 \\
\hline & NEK2 & + & 2 & 1.30 & 0.01 \\
\hline & NCAPG & + & 2 & 1.18 & $<0.01$ \\
\hline & DLGAP5 & + & 2 & 1.54 & $<0.01$ \\
\hline & GBP1 & + & 2 & 1.45 & $<0.01$ \\
\hline \multirow[t]{23}{*}{ Phase II } & STAT1 & - & 9 & -1.03 & 0.02 \\
\hline & CXCL10 & - & 6 & -2.16 & 0.02 \\
\hline & CXCL12 & - & 6 & -1.48 & 0.04 \\
\hline & $\mathrm{DCN}$ & - & 6 & -1.37 & 0.01 \\
\hline & CCL2 & - & 5 & -1.54 & 0.01 \\
\hline & KIT & - & 5 & -1.26 & 0.05 \\
\hline & IGF1 & - & 5 & -1.86 & $<0.01$ \\
\hline & OAS2 & - & 4 & -1.37 & 0.01 \\
\hline & IRF7 & - & 4 & -1.08 & 0.01 \\
\hline & ISG15 & - & 4 & -1.83 & 0.02 \\
\hline & FN1 & - & 4 & -1.34 & 0.04 \\
\hline & $\mathrm{HGF}$ & - & 4 & -1.22 & 0.02 \\
\hline & HERC6 & - & 3 & -1.71 & $<0.01$ \\
\hline & MX2 & - & 3 & -1.86 & 0.01 \\
\hline & IFIT3 & - & 3 & -1.79 & $<0.01$ \\
\hline & IFIT1 & - & 3 & -2.96 & $<0.01$ \\
\hline & GBP1 & - & 3 & -1.20 & 0.01 \\
\hline & CDC6 & + & 3 & 1.40 & 0.01 \\
\hline & IFIT5 & - & 2 & -1.11 & $<0.01$ \\
\hline & IFI6 & - & 2 & -1.55 & 0.01 \\
\hline & SP110 & - & 2 & -1.43 & $<0.01$ \\
\hline & IFI44 & - & 2 & -1.87 & $<0.01$ \\
\hline & DDX60 & - & 2 & -1.18 & $<0.01$ \\
\hline
\end{tabular}


Table I. Continued.

\begin{tabular}{|c|c|c|c|c|c|}
\hline Phase & Gene & Regulation & Counts & $\log \mathrm{FC}$ & P-value \\
\hline & IFIT2 & - & 2 & -1.67 & $<0.01$ \\
\hline & RSAD2 & - & 2 & -2.66 & $<0.01$ \\
\hline \multirow[t]{30}{*}{ Phase III } & BIRC5 & + & 9 & 1.13 & $<0.01$ \\
\hline & TOP2A & + & 8 & 1.36 & $<0.01$ \\
\hline & KIF2C & + & 6 & 1.04 & $<0.01$ \\
\hline & MCM10 & + & 6 & 1.16 & 0.01 \\
\hline & VEGFA & + & 6 & 1.27 & $<0.01$ \\
\hline & MAD2L1 & + & 5 & 1.03 & $<0.01$ \\
\hline & KIF15 & + & 5 & 1.45 & $<0.01$ \\
\hline & ASPM & + & 5 & 1.70 & $<0.01$ \\
\hline & FOXM1 & + & 5 & 1.18 & 0.01 \\
\hline & MX2 & + & 4 & 1.34 & 0.01 \\
\hline & STAT1 & + & 4 & 1.20 & $<0.01$ \\
\hline & PLXNA4 & - & 4 & -1.15 & 0.01 \\
\hline & $\mathrm{AR}$ & - & 4 & -1.69 & $<0.01$ \\
\hline & CCND1 & - & 3 & 1.20 & $<0.01$ \\
\hline & OAS2 & + & 3 & 1.05 & $<0.01$ \\
\hline & ACLY & + & 3 & 1.55 & 0.01 \\
\hline & GNG2 & + & 3 & -1.21 & $<0.01$ \\
\hline & RSAD2 & + & 2 & 1.85 & $<0.01$ \\
\hline & ISG15 & + & 2 & 1.82 & $<0.01$ \\
\hline & IFI35 & + & 2 & 1.35 & 0.01 \\
\hline & IRF5 & + & 2 & 1.46 & $<0.01$ \\
\hline & SAMHD1 & + & 2 & 1.05 & $<0.01$ \\
\hline & MKI67 & + & 2 & 1.20 & $<0.01$ \\
\hline & PLK4 & + & 2 & 1.03 & 0.01 \\
\hline & AHCTF1 & + & 2 & 1.03 & $<0.01$ \\
\hline & NUDC & + & 2 & 1.07 & $<0.01$ \\
\hline & EXO1 & + & 2 & 1.29 & $<0.01$ \\
\hline & PLXNA3 & + & 2 & 1.01 & 0.01 \\
\hline & MMP9 & + & 2 & 2.55 & $<0.01$ \\
\hline & PLAUR & + & 2 & 1.01 & $<0.01$ \\
\hline \multirow[t]{20}{*}{ Phase IV } & PIK3CA & + & 9 & 1.42 & $<0.01$ \\
\hline & CXCL8 & + & 8 & 1.28 & 0.05 \\
\hline & ITGB1 & + & 8 & 2.20 & $<0.01$ \\
\hline & PTK2 & + & 8 & 1.33 & $<0.01$ \\
\hline & GNG2 & + & 6 & 1.18 & 0.05 \\
\hline & ITGA1 & + & 6 & 1.33 & $<0.01$ \\
\hline & GNG12 & - & 6 & -1.14 & $<0.01$ \\
\hline & FOS & - & 5 & -1.13 & 0.05 \\
\hline & EDN1 & + & 5 & 1.07 & $<0.01$ \\
\hline & NMU & - & 4 & -2.23 & $<0.01$ \\
\hline & LPAR5 & - & 4 & -1.36 & $<0.01$ \\
\hline & STAT1 & + & 3 & 1.75 & $<0.01$ \\
\hline & FN1 & + & 3 & 3.61 & $<0.01$ \\
\hline & GSTM1 & - & 3 & -1.09 & 0.02 \\
\hline & PLA2G4A & - & 3 & -1.41 & 0.02 \\
\hline & CXCR4 & + & 2 & 1.58 & $<0.01$ \\
\hline & HCAR3 & - & 2 & -1.60 & $<0.01$ \\
\hline & S1PR5 & - & 2 & -1.56 & $<0.01$ \\
\hline & CXCL5 & - & 2 & -2.10 & 0.01 \\
\hline & NQO1 & - & 2 & -1.38 & 0.01 \\
\hline
\end{tabular}


Table I. Continued.

\begin{tabular}{llcrr}
\hline Phase & Gene & Regulation & Counts & LogFC \\
\hline CXCL11 & + & 2 & 1.69 & 0.02 \\
COMP & + & 2 & 1.62 & 0.01 \\
MAPK12 & + & 2 & 1.38 & $<0.01$
\end{tabular}

+, upregulated; -, downregulated.

examining the key pathways, in order to determine which pathway contained at least one of the key genes.

Co-expression and survival analysis for key genes. To identify the co-expression of key genes and their impact on OS time, the LinkedOmics database (68) was used, which was based on TCGA (69). The co-expression analysis was performed using Pearson correlation and OS analysis was assessed with Cox regression method. For survival analysis, samples were divided by the median value of the investigated gene. $\mathrm{P}<0.05$ was considered to indicate a statistically significant difference for both the co-expression correlation and OS time.

\section{Results}

Identification of DEGs. Analysis of the GSE63514 dataset using GEO2R, with a criteria of $\geq 2$ FC and $\mathrm{P}<0.05$, identified a total of 3,446 DEGs for the four phases as follows: 446 DEGs in phase I, of which 76 were upregulated and 370 were downregulaged; 382 DEGs in phase II, of which 146 were upregulated and 236 were downregulated; 756 DEGs in phase III, of which 435 were upregulated and 321 were downregulated; 1,862 DEGs in phase IV, of which 816 were upregulated and 1046 were downregulated.

Identification of hub genes. Following removal of 2,256 irrelevant genes (Phase I, 265; Phase II, 197; Phase III, 603; Phase IV, 1191), 12 topological algorithms were used and the top 10 genes for each method were extracted. A total of 107 genes that appeared at least twice were conserved as hub genes, as presented in Table I. A total of 29 genes were identified in phase I, among which five genes were members of the kinesin family (KIF11, KIF15, KIF23, KIF4A and $K I F 14)$, and five genes were associated with meiosis and the maturation of oocytes $[B U B 1 B(70), B U B 1$ (71), CCNA2 (72), $C C N B 1$ (72) and $C D K 1$ (73)], as well as other genes associated with inflammation and innate immune responses [STAT1 (74), GBPl (75) and RHOA (76)]. A total of 25 hub genes were verified in phase II, among which the involvement of seven interferon-induced genes was identified (IFI44L, IFIT3, IFIF1, IFIF5, IFI44, IFIT2 and IFI6), and several pattern recognition receptor-associated genes [IRF7 (77), STAT1 (78) and $C X C L 10$ (79)], as well as some genes involved in invasion and metastasis of cancer cells [HGF (80), IGF1 (81), KIT (82), FN1 (83) and CXCL12 (84)]. A number of common cancer-associated signaling pathway genes were identified in phase III [CCNDI (85), STAT1 (86) and VEGFA (87)]. A total of three $\mathrm{C}-\mathrm{X}-\mathrm{C}$ motif chemokine ligands (CXCL8, CXCL11 and $C X C L 4)$, two integrin subunits (ITGBI and ITGAI), and one mitogen-activated protein $(M A P K 12)$ were identified in phase IV. Furthermore, PIK3CA (88) and FOS (89) participated in cancer-associated pathways in phase IV. The diversity of genes within the four phases demonstrated that $\mathrm{CC}$ progression is a complex process and its molecular mechanisms are not constant.

GO enrichment analysis of hub genes. To further identify the biological functions and locations of hub genes, GO enrichment analysis (90) was performed (Fig. 2). Hub genes were notably enriched in 'biological regulation', 'metabolic process' and 'cellular component organization' in phase I and II, while 'responses to stimulus' and 'biological regulation' were predominantly enriched at phases III-IV in biological process. For the cellular components, 'nucleus', 'membrane-enclosed lumen' and 'macromolecular complex' was enriched at phases I-III, while 'chromosome' and 'membrane' was identified in phases II and IV, respectively. 'Protein binding' was enriched at all four phases for Molecular Function. Furthermore, 'nucleic acid binding' and 'hydrolase activity' were enriched at phase II and III, while 'ion binding' was enriched at phase III and IV.

Pathway enrichment analysis of hub genes. As presented in Table II, a total of 10 notably enriched pathways were identified at phase I, of which five pathways were associated with virus infections including, 'influenza A', 'tuberculosis', 'herpes simplex infection', 'viral carcinogenesis' and 'Epstein-Barr virus infection', and additional pathways involved in the 'cell cycle', 'oocyte meiosis' and 'progesterone-mediated oocyte maturation'. Furthermore, the chemokine signaling pathway was also identified in phase I. The RIG-I-like receptor and Toll-like receptor signaling pathways were identified in phase II, and are associated with pattern-recognition receptors (91). In addition, several pathways, including 'focal adhesion', 'Rap1 signaling pathway', 'Ras signaling pathway', 'PI3K-Akt signaling pathway' and 'Proteoglycans in cancer' were associated with invasion and metastasis (92-96). The two common cancer-associated signaling pathways 'Pathways in cancer' and 'Proteoglycans in cancer', were enriched in phase III, while 70 pathways were significant enriched at phase IV $(\mathrm{P}<0.05)$. Apart from the common cancer-associated signaling pathways and virus infection pathways at phase IV, the 'IL-17 signaling pathway', 'VEGF signaling pathway' and 'endocrine resistance' also were also demonstrated to be associated with CC progression. Furthermore, the 'AGE-RAGE 

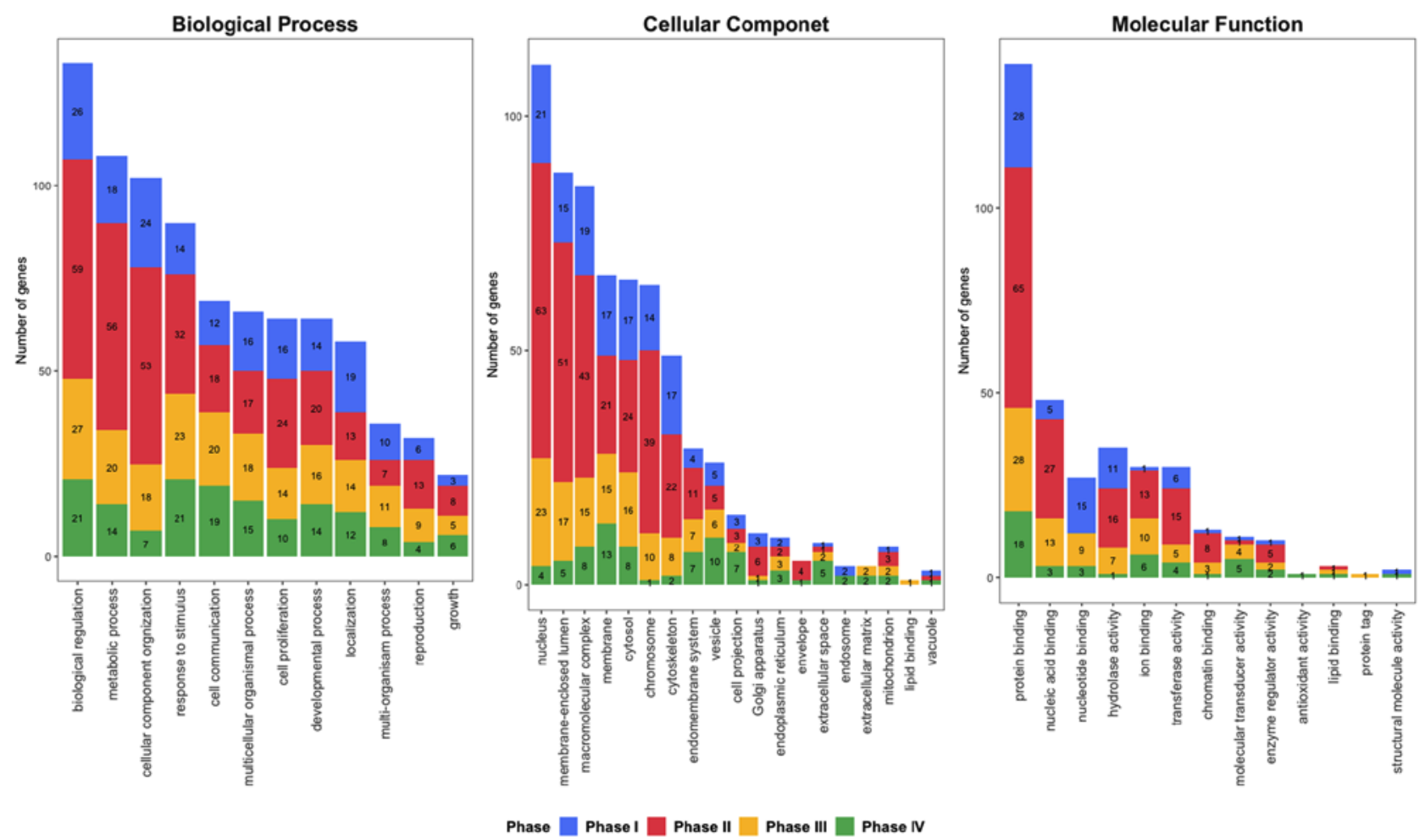

Figure 2. Gene ontology enrichment analysis of hub genes for phase I, II, III and IV. The number in each phase represents the gene count.

signaling pathway in diabetic complications' was also identified at phases II-IV.

Pathway crosstalk analysis. The pathway crosstalk analysis results are presented in Fig. S1. A total of two major modules were identified in phase I, one of which was predominantly associated with inflammatory responses to viral infections, such as the NOD-like receptor signaling pathway and the chemokine signaling pathway, while the other module was associated with cycle regulation of oocytes, including cell cycle, progesterone-mediated oocyte maturation and oocyte meiosis (Fig. S1A). Similarly, the pathways were grouped into two modules in phase II. One module consisted of immune responses (RIG-I-like receptor and Toll-like receptor signaling pathways, and NOD-like receptor signaling pathway), which may trigger rapid activation of innate immunity by inducing the production of proinflammatory cytokines (97-99). The other module was predominantly involved in the regulation of cell proliferation and invasion (Ras signaling pathway, PI3K-Akt signaling pathway, Rap1 signaling pathway, focal adhesion and other cancer-associated signaling pathways) (Fig. S1B). Notably, the two modules in phases I and II were not independent as they were demonstrated to connect with each other via several signaling pathways. All pathways formed a cluster and common cancer-associated signaling pathways were indicated to play a critical role in phase III (Fig. S1C), while the connection between the pathways became highly complex in phase IV (Fig. S1D). The possible molecular mechanisms, such as inflammation caused by virus infections, pathways associated with cell invasion, IL-17 and VEGF signaling pathways, and endocrine resistance, are associated with one another. These results further verified the complexity of CC. A comprehensive combination of pathway crosstalk analysis containing 47 nodes and 105 edges among the four phases is presented in Fig. 3A. By analyzing the nodes with degrees $\geq 5$, a subnetwork containing 11 key pathways was extracted (Fig. 3B). It indicates that the MAPK signaling pathway (degree=33), PI3K-Akt signaling pathway (degree=21) and focal adhesion (degree=15), which are ranked as the top three nodes and most interactive, may play critical roles in the progression of CC.

PPI network analysis. A PPI network containing 51 nodes and 78 edges was constructed (Fig. 4A) by downloading the hub genes into the PINA database. Based on the description of a previous study (59), which defined the main nodes as nodes with degree $>5,14$ key genes were identified from the PPI network (Fig. 4B). CDK1, FN1 and ITGB1 rank first, second and third, respectively, as the top three-degree levels $(16,12$ and 8 , respectively). STATl was the only gene demonstrated to be involved at all four phases. Furthermore, $M M P 9$ presented self-regulating functions and was demonstrated to co-express with $F N 1$ and ITGBI.

Comprehensive gene-pathway analysis. After mapping the key genes onto the key pathways using the KEGG and BioCarta databases, a potential gene-pathway flowchart, including eight key pathways and six key genes was constructed (Fig. 5). The results demonstrated the following: For phase I, $C D K I$ and $C C N B 1$ participated in the regulation of the cell cycle, while $C D K 1$ was also involved in viral carcinogenesis; for phases II-IV, 'pathways in cancer,' 'focal adhesion' and 'PI3K-Akt signaling pathway' were ranked the top three pathways according to the number of genes involved; FN1, ITGBI 
Table II. Pathway enrichment analysis for phases I-IV.

\begin{tabular}{|c|c|c|c|}
\hline Phase & Pathway & FDR & Involved genes \\
\hline \multirow[t]{10}{*}{ Phase I } & Cell cycle & $<0.001$ & CDK1, TTK, CCNA2, BUB1, CCNB1, BUB1B \\
\hline & Progesterone-mediated oocyte maturation & 0.002 & CDK1, CCNA2, BUB1, CCNB1 \\
\hline & Chemokine signaling pathway & 0.006 & RHOA, CXCL10, STAT1, GNG2 \\
\hline & Oocyte meiosis & 0.018 & CDK1, BUB1, CCNB1 \\
\hline & NOD-like receptor signaling pathway & 0.036 & RHOA, GBP1, STAT1 \\
\hline & Influenza A & 0.036 & HLA-DPA1, CXCL10, STAT1 \\
\hline & Tuberculosis & 0.037 & RHOA, HLA-DPA1, STAT1 \\
\hline & Herpes simplex infection & 0.038 & CDK1, HLA-DPA1, STAT1 \\
\hline & Viral carcinogenesis & 0.044 & RHOA, CDK1, CCNA2 \\
\hline & Epstein-Barr virus infection & 0.044 & CDK1, HLA-DPA1, CCNA2 \\
\hline \multirow[t]{19}{*}{ Phase II } & Influenza A & $<0.001$ & $\begin{array}{l}\text { CCL2, OAS2, IRF7, RSAD2, CXCL10, } \\
\text { STAT1 }\end{array}$ \\
\hline & NOD-like receptor signaling pathway & $<0.001$ & GBP1, CCL2, OAS2, IRF7, STAT1 \\
\hline & Herpes simplex infection & $<0.001$ & CCL2, OAS2, IRF7, IFIT1, STAT1 \\
\hline & Pathways in cancer & 0.001 & HGF, IGF1, FN1, KIT, CXCL12, STAT1 \\
\hline & Hepatitis C & 0.001 & OAS2, IRF7, IFIT1, STAT1 \\
\hline & Cytokine-cytokine receptor interaction & 0.001 & HGF, CCL2, KIT, CXCL10, CXCL12 \\
\hline & RIG-I-like receptor signaling pathway & 0.003 & IRF7, ISG15, CXCL10 \\
\hline & Chemokine signaling pathway & 0.003 & CCL2, CXCL10, CXCL12, STAT1 \\
\hline & Genes encoding secreted soluble factors & 0.003 & HGF, CCL2, IGF1, CXCL10, CXCL12 \\
\hline & Proteoglycans in cancer & 0.004 & HGF, IGF1, FN1, DCN \\
\hline & $\begin{array}{l}\text { AGE-RAGE signaling pathway in diabetic } \\
\text { complications }\end{array}$ & 0.005 & CCL2, FN1, STAT1 \\
\hline & Toll-like receptor signaling pathway & 0.006 & IRF7, CXCL10, STAT1 \\
\hline & $\begin{array}{l}\text { Ensemble of genes encoding extracellular matrix } \\
\text { and extracellular matrix-associated proteins }\end{array}$ & 0.008 & $\begin{array}{l}\text { HGF, CCL2, IGF1, FN1, DCN, CXCL10, } \\
\text { CXCL12 }\end{array}$ \\
\hline & Measles & 0.009 & OAS2, IRF7, STAT1 \\
\hline & PI3K-Akt signaling pathway & 0.015 & HGF, IGF1, FN1, KIT \\
\hline & Focal adhesion & 0.024 & HGF, IGF1, FN1 \\
\hline & Rap1 signaling pathway & 0.026 & HGF, IGF1, KIT \\
\hline & Ras signaling pathway & 0.029 & HGF, IGF1, KIT \\
\hline & $\begin{array}{l}\text { Ensemble of genes encoding ECM-associated } \\
\text { proteins including ECM-affilaited proteins, ECM } \\
\text { regulators and secreted factors }\end{array}$ & 0.032 & HGF, CCL2, IGF1, CXCL10, CXCL12 \\
\hline \multirow[t]{6}{*}{ Phase III } & Pathways in cancer & 0.002 & $\begin{array}{l}\text { BIRC5, CCND1, MMP9, AR, STAT1, GNG2, } \\
\text { VEGFA }\end{array}$ \\
\hline & Bladder cancer & 0.006 & CCND1, MMP9, VEGFA \\
\hline & Hepatitis B & 0.011 & BIRC5, CCND1, MMP9, STAT1 \\
\hline & Pancreatic cancer & 0.012 & CCND1, STAT1, VEGFA \\
\hline & Proteoglycans in cancer & 0.025 & PLAUR, CCND1, MMP9, VEGFA \\
\hline & $\begin{array}{l}\text { AGE-RAGE signaling pathway in diabetic } \\
\text { complications }\end{array}$ & 0.027 & CCND1, STAT1, VEGFA \\
\hline \multirow[t]{6}{*}{ Phase IV } & Chemokine signaling pathway & $<0.001$ & $\begin{array}{l}\text { GNG12, CXCL11, CXCL5, PIK3CA, CXCR4, } \\
\text { PTK2, STAT1, CXCL8, GNG2 }\end{array}$ \\
\hline & Pathways in cancer & $<0.001$ & $\begin{array}{l}\text { FN1, LPAR5, GNG12, ITGB1, PIK3CA, } \\
\text { CXCR4, FOS, PTK2, STAT1, CXCL8, GNG2 }\end{array}$ \\
\hline & Fluid shear stress and atherosclerosis & $<0.001$ & $\begin{array}{l}\text { GSTM1, NQO1, MAPK12, PIK3CA, FOS, } \\
\text { EDN1, PTK2 }\end{array}$ \\
\hline & Signaling of Hepatocyte Growth Factor Receptor & $<0.001$ & ITGA1, ITGB1, PIK3CA, FOS, PTK2 \\
\hline & PI3K-Akt signaling pathway & $<0.001$ & $\begin{array}{l}\text { ITGA1, FN1, COMP, LPAR5, GNG12, ITGB1, } \\
\text { PIK3CA, PTK2, GNG2 }\end{array}$ \\
\hline & B Cell Survival Pathway & $<0.001$ & ITGA1, ITGB1, PIK3CA, FOS \\
\hline
\end{tabular}


Table II. Continued.

\begin{tabular}{|c|c|c|c|}
\hline Phase & Pathway & FDR & Involved genes \\
\hline & $\begin{array}{l}\text { AGE-RAGE signaling pathway in diabetic } \\
\text { complications }\end{array}$ & $<0.001$ & $\begin{array}{l}\text { MAPK12, FN1, PIK3CA, EDN1, STAT1, } \\
\text { CXCL8 }\end{array}$ \\
\hline & Toll-like receptor signaling pathway & $<0.001$ & $\begin{array}{l}\text { MAPK12, CXCL11, PIK3CA, FOS, STAT1, } \\
\text { CXCL8 }\end{array}$ \\
\hline & $\begin{array}{l}\text { Aspirin Blocks Signaling Pathway Involved in } \\
\text { Platelet Activation }\end{array}$ & $<0.001$ & PLA2G4A, ITGA1, ITGB1, PTK2 \\
\hline & $\begin{array}{l}\text { Erk and PI-3 Kinase Are Necessary for Collagen } \\
\text { Binding in Corneal Epithelia }\end{array}$ & $<0.001$ & ITGA1, ITGB1, PIK3CA, PTK2 \\
\hline & Pertussis & $<0.001$ & MAPK12, CXCL5, ITGB1, FOS, CXCL8 \\
\hline & Focal adhesion & $<0.001$ & ITGA1, FN1, COMP, ITGB1, PIK3CA, PTK2 \\
\hline & TNF signaling pathway & $<0.001$ & MAPK12, CXCL5, PIK3CA, FOS, EDN1 \\
\hline & Leukocyte transendothelial migration & $<0.001$ & MAPK12, ITGB1, PIK3CA, CXCR4, PTK2 \\
\hline & Regulation of actin cytoskeleton & $<0.001$ & ITGA1, FN1, GNG12, TGB1, PIK3CA, PTK2 \\
\hline & VEGF signaling pathway & $<0.001$ & PLA2G4A, MAPK12, PIK3CA, PTK2 \\
\hline & PTEN dependent cell cycle arrest and apoptosis & $<0.001$ & ITGB1, PIK3CA, PTK2 \\
\hline & uCalpain and friends in Cell spread & $<0.001$ & ITGA1, ITGB1, PTK2 \\
\hline & Trefoil Factors Initiate Mucosal Healing & $<0.001$ & ITGB1, PIK3CA, PTK2 \\
\hline & Prolactin signaling pathway & $<0.001$ & MAPK12, PIK3CA, FOS, STAT1 \\
\hline & Leishmaniasis & $<0.001$ & MAPK12, ITGB1, FOS, STAT1 \\
\hline & Inhibition of Cellular Proliferation by Gleevec & $<0.001$ & PIK3CA, FOS, STAT1 \\
\hline & CXCR4 Signaling Pathway & $<0.001$ & PIK3CA, CXCR4, PTK2 \\
\hline & TPO Signaling Pathway & $<0.001$ & PIK3CA, FOS, STAT1 \\
\hline & Bacterial invasion of epithelial cells & $<0.001$ & FN1, ITGB1, PIK3CA, PTK2 \\
\hline & mCalpain and friends in Cell motility & $<0.001$ & ITGA1, ITGB1, PTK2 \\
\hline & ECM-receptor interaction & $<0.001$ & ITGA1, FN1, COMP, ITGB1 \\
\hline & Small cell lung cancer & $<0.001$ & FN1, ITGB1, PIK3CA, PTK2 \\
\hline & EGF Signaling Pathway & $<0.001$ & PIK3CA, FOS, STAT1 \\
\hline & IL-17 signaling pathway & $<0.001$ & MAPK12, CXCL5, FOS, CXCL8 \\
\hline & PDGF Signaling Pathway & $<0.001$ & PIK3CA, FOS, STAT1 \\
\hline & Amoebiasis & $<0.001$ & FN1, PIK3CA, PTK2, CXCL8 \\
\hline & Endocrine resistance & $<0.001$ & MAPK12, PIK3CA, FOS, PTK2 \\
\hline & Proteoglycans in cancer & $<0.001$ & MAPK12, FN1, ITGB1, PIK3CA, PTK2 \\
\hline & Chagas disease (American trypanosomiasis) & $<0.001$ & MAPK12, PIK3CA, FOS, CXCL8 \\
\hline & Agrin in Postsynaptic Differentiation & $<0.001$ & ITGA1, ITGB1, PTK2 \\
\hline & Integrin Signaling Pathway & $<0.001$ & ITGA1, ITGB1, PTK2 \\
\hline & Fc Epsilon Receptor I Signaling in Mast Cells & $<0.001$ & PLA2G4A, PIK3CA, FOS \\
\hline & Cholinergic synapse & $<0.001$ & GNG12, PIK3CA, FOS, GNG2 \\
\hline & Platelet activation & 0.001 & PLA2G4A, MAPK12, ITGB1, PIK3CA \\
\hline & Osteoclast differentiation & 0.001 & MAPK12, PIK3CA, FOS, STAT1 \\
\hline & Dopaminergic synapse & 0.001 & MAPK12, GNG12, FOS, GNG2 \\
\hline & Hepatitis C & 0.001 & MAPK12, PIK3CA, STAT1, CXCL8 \\
\hline & Cytokine-cytokine receptor interaction & 0.001 & CXCL11, CXCL5, CXCR4, ACKR3, CXCL8 \\
\hline & Hepatitis B & 0.001 & PIK3CA, FOS, STAT1, CXCL8 \\
\hline & Phospholipase D signaling pathway & 0.001 & PLA2G4A, LPAR5, PIK3CA, CXCL8 \\
\hline & Shigellosis & 0.001 & MAPK12, ITGB1, CXCL8 \\
\hline & Fc epsilon RI signaling pathway & 0.002 & PLA2G4A, MAPK12, PIK3CA \\
\hline & Influenza A & 0.002 & MAPK12, PIK3CA, STAT1, CXCL8 \\
\hline & Axon guidance & 0.002 & ITGB1, PIK3CA, CXCR4, PTK2 \\
\hline & Integrin Signaling Pathway & 0.002 & ITGA1, PIK3CA, PTK2 \\
\hline & Salmonella infection & 0.003 & MAPK12, FOS, CXCL8 \\
\hline & MAPKinase Signaling Pathway & 0.003 & MAPK12, FOS, STAT1 \\
\hline & Rap1 signaling pathway & 0.003 & MAPK12, LPAR5, ITGB 1, PIK3CA \\
\hline
\end{tabular}


Table II. Continued.

\begin{tabular}{lll}
\hline \multicolumn{1}{c}{ Phase } & FDR & Involved genes \\
\hline Rheumatoid arthritis & 0.003 & CXCL5, FOS, CXCL8 \\
Th1 and Th2 cell differentiation & 0.003 & MAPK12, FOS, STAT1 \\
Circadian entrainment & 0.003 & GNG12, FOS, GNG2 \\
Inflammatory mediator regulation of TRP & 0.003 & PLA2G4A, MAPK12, PIK3CA \\
channels & & \\
Ras signaling pathway & 0.003 & PLA2G4A, GNG12, PIK3CA, GNG2 \\
Choline metabolism in cancer & 0.003 & PLA2G4A, PIK3CA, FOS \\
Retrograde endocannabinoid signaling & 0.003 & MAPK12,GNG12,GNG2 \\
T cell receptor signaling pathway & 0.004 & MAPK12, PIK3CA, FOS \\
Th17 cell differentiation & 0.004 & MAPK12, FOS, STAT1 \\
Serotonergic synapse & 0.004 & PLA2G4A, GNG12, GNG2 \\
Toxoplasmosis & 0.004 & MAPK12, ITGB1, STAT1 \\
Glutamatergic synapse & 0.004 & PLA2G4A, GNG12, GNG2 \\
MAPK signaling pathway & 0.004 & PLA2G4A, MAPK12, GNG12, FOS \\
Sphingolipid signaling pathway & 0.005 & S1PR5, MAPK12, PIK3CA \\
NOD-like receptor signaling pathway & 0.012 & MAPK12, STAT1, CXCL8 \\
cAMP signaling pathway & 0.018 & HCAR3, PIK3CA, FOS
\end{tabular}

FDR, false discovery rate.
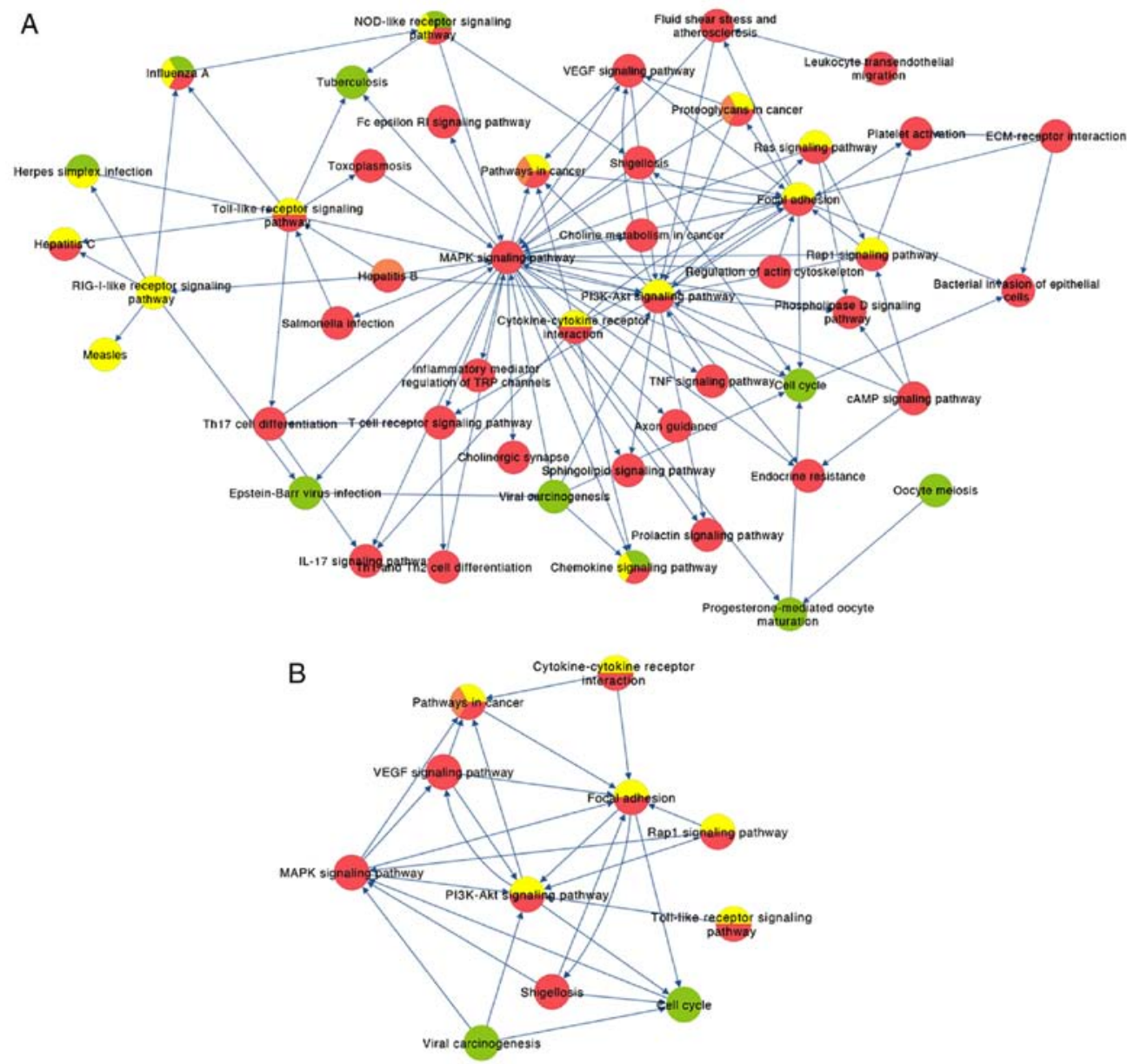

Figure 3. Comprehensive pathways crosstalk analysis. (A) Combination of pathways crosstalk analysis for the four phases and the (B) subnetwork with nodal degree $\geq 5$. Green, phase I; yellow, phase II; orange, phase III; red, phase IV. The arrow represents the up/downstream associations between the pathways. MAPK signaling pathway (degree=33), PI3K-Akt signaling pathway (degree=21) and Focal adhesion (degree=15) rank as the top three pathways, whereby the majority of other pathways transfer information with them. 


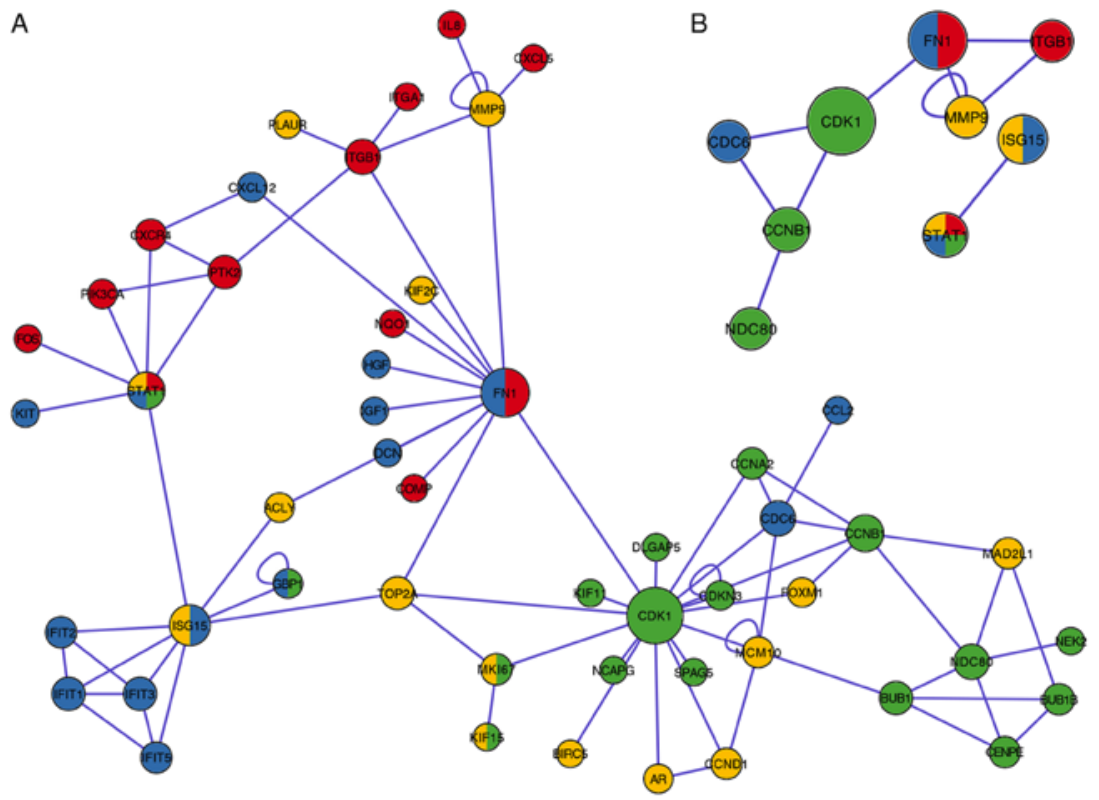

Figure 4. Protein-protein interaction network analysis. (A) Protein-protein interaction network downloaded from The Protein Interaction Network Analysis platform and (B) subnetwork with nodal degree $\geq 5$. Green, phase I; blue, phase II; yellow, phase II; red, phase IV. The nodal size represents the degree of each node. CDK1 (degree=16), FN1 (degree=12) and ITGB1 (degree=8) rank as the top three proteins. MMP9 was self-regulated and co-expressed with FN1 and ITGB1.

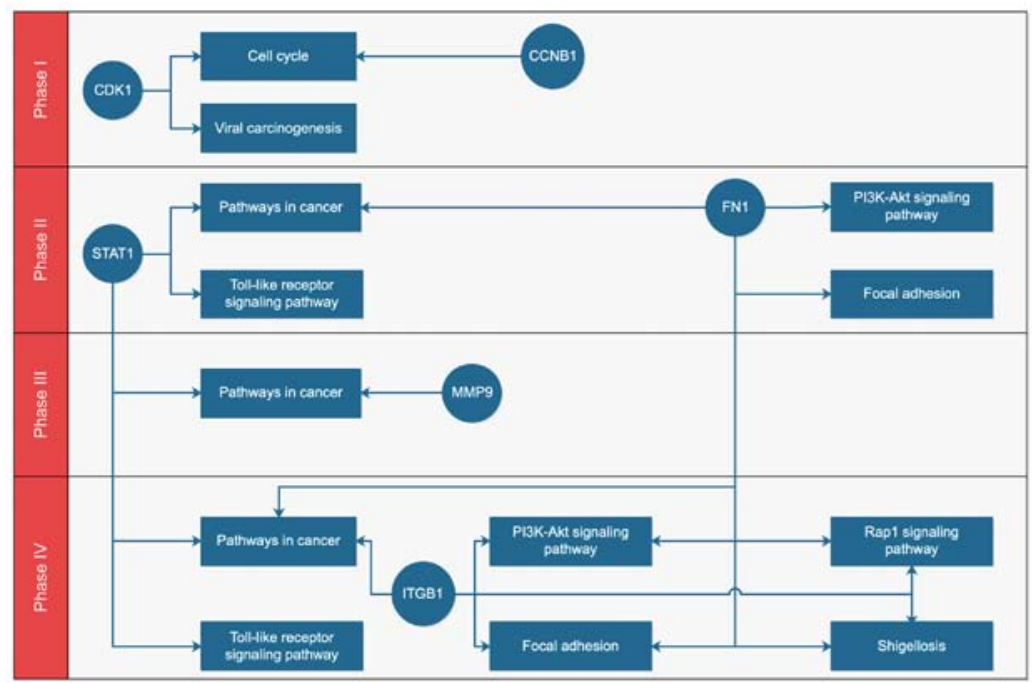

Figure 5. Gene-pathway flowchart for the key genes and the pathways in phases I-IV. Circle, gene; rectangle, pathway. CDK1 and CCNB1 regulate the cell cycle and they are activated in phase I. For phases II-IV, 'pathways in cancer', 'focal adhesion' and 'PI3K-Akt signaling pathway' rank as the top three pathways according to the number of genes involved.

and $M M P 9$ may be associated with metastasis of tumor cells, and STATI participated in 'pathways in cancer' and 'Toll-like receptor signaling pathway', which functioned at a phase IV.

Co-expression network and survival analysis for key genes. By mining the data from LinkedOmics, the results of co-expression demonstrated that $C D K 1$ had a significantly positive correlation with $C C N B 1(\mathrm{P}<0.0001)$, but negative correlation with $F N 1(\mathrm{P}=0.003)$ and $M M P 9(\mathrm{P}=0.001)$, respectively (Fig. 6). $C C N B 1$ demonstrated a significantly negative correlation with ITGBI ( $\mathrm{P}=0.047)$; however, FN1, ITGBI and $M M P 9$ indicated a significantly positive correlation between each other (FN1 and ITGB1, P<0.001; FN1 and MMP9,
$\mathrm{P}<0.0001$; ITGB1 and MMP9, $\mathrm{P}=0.023)$. STAT1 was significantly positively correlated with $M M P 9(\mathrm{P}<0.0001)$.

Survival analysis indicated that patients with higher $F N 1$ and ITGBI expression levels had a significantly worse OS time (FN1, $\mathrm{P}=0.00080 ;$ ITGB1, $\mathrm{P}=0.00005$; Fig. 7). However, $C D K 1, C C N B 1, M M P 9$ and STATl were not demonstrated to have a significant effect on OS.

\section{Discussion}

To date, the occurrence and development of $\mathrm{CC}$ is hypothesized to be linked with persistent HPV infection (100); however, the specific molecular mechanisms require further investigation. 


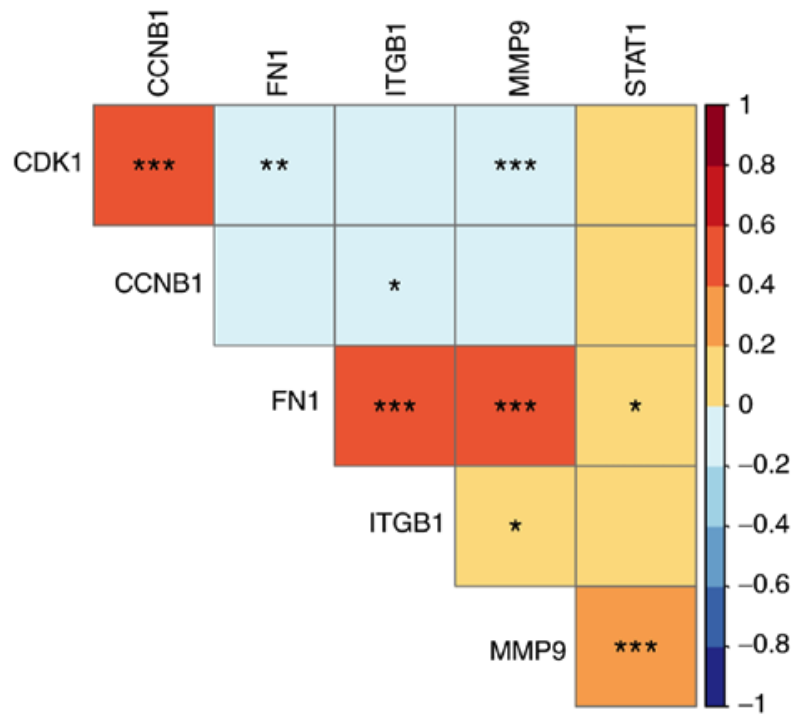

Figure 6. Co-expression analyses for the key genes. Positive correlation was detected between CDK1 and CCNB1; between FN1 and ITGB1, and MMP9, and between STAT1 and MMP9. Color in each grid represents the correlation coefficient between two genes. The values in the color legend represent the correlation coefficient. ${ }^{*} \mathrm{P}<0.05,{ }^{* *} \mathrm{P}<0.01,{ }^{* * * *} \mathrm{P}<0.001$

In addition, although a number of studies are examining the molecular mechanisms of CC (101-104), the detailed pathological process remains unclear.

The results of the present study indicated that $C D K 1$ had the highest degree, and participated in the cell cycle with $C C N B 1$ and viral carcinogenesis in phase I. CDK1 is one of the major cell cycle regulatory proteins and operates at the center of the cell cycle regulatory network (105). It regulates the G-S phase transition and initiates DNA replication (106). Furthermore, as a core molecule at the $\mathrm{M}$ phase checkpoint, $C D K 1$ plays a role in the regulation of $G_{2}$ phase, at $M$ phase in the cell cycle (107). The HPV infection pathway is regulated within the viral carcinogenesis pathway (19). E6 proteins inactivate p53 by binding (108), while p53 negatively regulates $C D K 1$ transcription under normal physiological conditions (109). In addition, the activation of cyclin B1-CDK1 is the key event that initiates the start of mitosis (110). Centrosome separation can be regulated by $C D K 1$ (111), and cyclin B1-CDK1 remains activated following centrosome separation (110). Hence, overexpression of $C D K 1$ can cause dysfunction in cell cycle progression, failure of normal proliferation and differentiation, and thereby lead to malignant proliferation of cancer cells and the formation of CC. CCNBI is a notable member of the cyclin family, a key initiator and a stringent quality control step of mitosis (112). It also plays a key role in the regulation of $C D K 1$, and its phosphorylated substrates can promote the transition of the cell cycle from $\mathrm{G}_{2}$ to mitosis $(113,114)$. Amplification of the HPV genome depends on prolongation of the $\mathrm{G}_{2}$ phase in the cell cycle (115). CCNBl is a downstream target of STAT3, which is a key gene that regulates the proliferation and differentiation of CC cells (116). In cells with inactivated STAT3, CCNB1 expression is downregulated and amplification of the HPV genome is also decreased, resulting in decreased activity of CC cells (116). As the results of the present study demonstrated that $C D K 1$ and $C C N B 1$ occurred in phase $I$ and functioned as regulators of proliferation and differentiation, they may be potential promoters of CIN and $\mathrm{CC}$.

In the process of tumor invasion and metastasis, cancer cells can bind to ligands of the extracellular matrix (ECM) via integrins and degrade the basement membrane (BM) by secreting proteases via the pathways of focal adhesion and the PI3K-Akt signaling pathway (117). This degradation is also the prerequisite for stromal infiltration and cancer cell migration (118). ITGB1 belongs to the integrin family and FN1 is the ligand. The binding of ITGBI and FNI induces the phosphorylation of tyrosine and directly affects cytoskeleton reconstruction and signal transduction activities of the Ras-MAPK signaling pathway via the $R A P 1$ signaling pathway, which initiates the expression of MMP genes (119). MMPs are a family of calcium and zinc-dependent proteases that degrade a variety of components of the ECM (120). Collagen type IV is the main scaffold in the BM of the ECM and also the main substrate of MMP9 (121). MMP9 can decompose the nestin in the BM to destroy the cells integrity and promote the invasion and metastasis of cancer cells (122). MMP9 expression in HPV-positive patients with CC is higher than in HPV-negative patients (123). Cardeal et al (124) reported that MMP9 is upregulated in human keratinocytes expressing the HPV16 E7 protein. This may be due to TIMP2, an inhibitor of $M M P 9$, which could be downregulated by HPV16 E7. It was also demonstrated that HPV can directly regulate the activity of $M M P 9$ in lung cancer cells (125). There may be an association between HPV infection and the MMP family, which may be beneficial in the diagnosis of cervical precancerous lesions and $\mathrm{CC}$ as $M M P 9$ may be considered as a novel biomarker. However, the specific molecular mechanisms require further investigation. As FN1 and ITGB1 were targets of miR-9-3p (126) and FN1 promoted migration and invasion by upregulating MMP9 in cancer (127), it is not surprising that these three genes are co-expressed as a reaction triplet. Furthermore, since higher levels of FN1 and ITGBI are significantly associated with lower OS rate, these two genes may be developed as novel prognostic factors for CC.

STAT1, the only gene that participates in all four phases, in the present study, is involved in the cancer pathway at phases II, III and IV. It has been reported that STATI is upregulated in both CIN1 and CC (128), and the results of the present study that STAT1 is upregulated in phase I, III and IV confirmed this finding. A previous study demonstrated that activated STAT1 plays a tumor suppressive role in breast cancer cells (129). Nevertheless, STAT1 also exerts tumor promoter effects under specific conditions (130). In some malignant diseases, including breast and lung cancers, STATI can act as an oncoprotein or a tumor suppressor of the same cell type based on the specific genetic background (130). In CC, STAT1 may have a protective effect in the early stages of HPV infection but may act as a proto-oncogene during the invasive phase of the disease (128). STAT1 can promote cancer cell death by activating p53 expression, and it plays a role in immunosurveillance, and the inhibition of angiogenesis and metastasis in cancer cells (130); however, STAT1 can also promote tumor invasion and metastasis in chronic inflammation (131). The effect of STATI in CC still remains unclear; therefore, further verification is required as it may be a key target for the treatment of CC. 

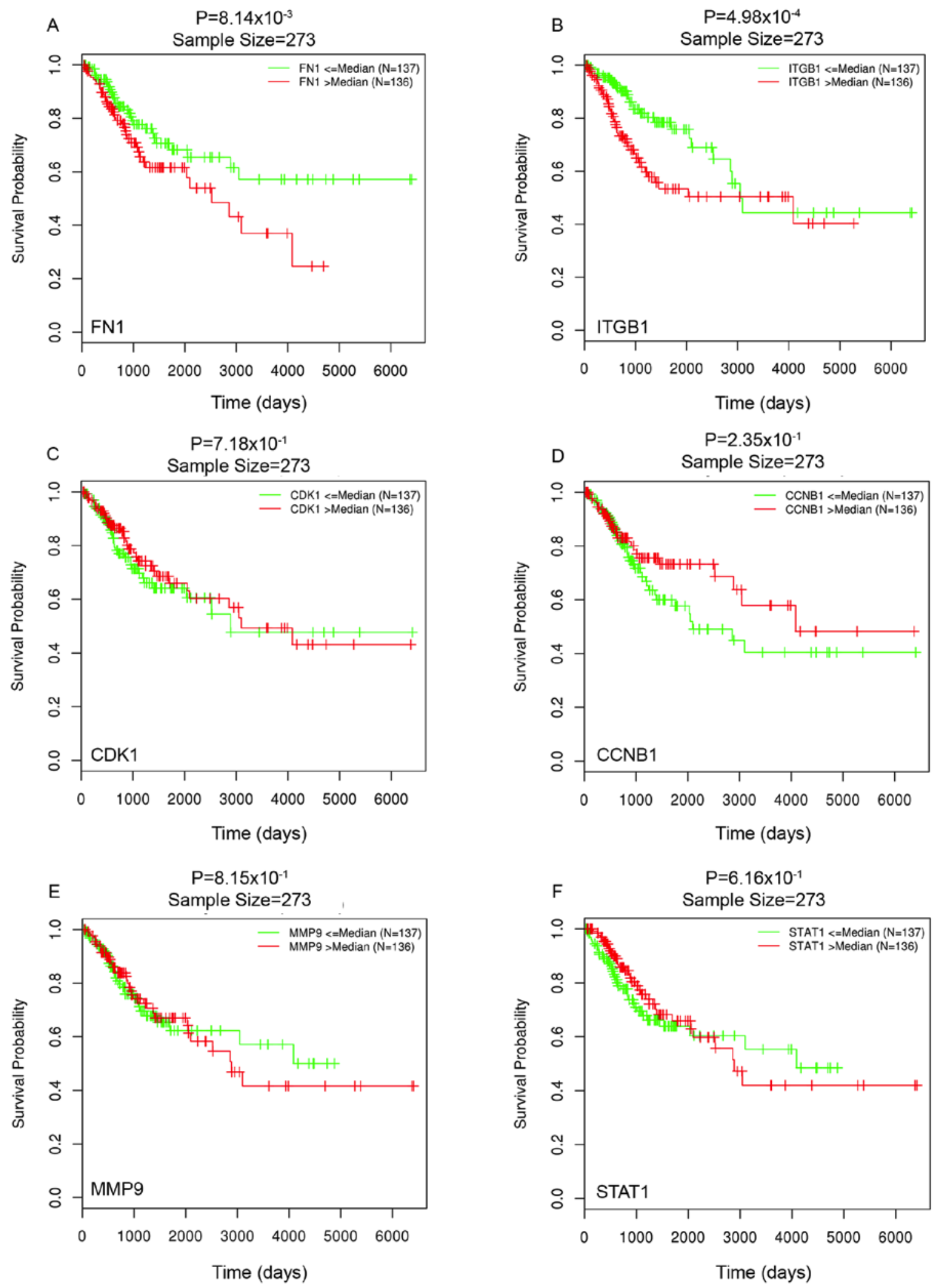

Figure 7. Survival analysis for the key genes. (A) FN1, (B) ITGB1, (C) CDK1 and (D) CCNB1, (E) MMP9 and (F) STAT1. ITGB1 and FN1 have significant effect on overall survival.

The current study presented several limitations. First, as this was an in-silico study, the identification of DEGs may change with additional data, thus the results of subsequent analyses may change accordingly. Secondly, some genes were excluded to decrease the false-positive rate; however, these genes may also have a vital effect on CC. Thirdly, although several genes associated with HPV infection (TP53TG1, $R A C 1, P A K 2$ and LTBP2) were identified in DEGs, HPV infection was not observed in the pathway analyses. This may be due to the fact that an insufficient amount of hub genes were 
identified, or the genes had a low or moderate effect on the HPV infection pathway.

In conclusion, the present study revealed that $C D K 1$, CCNB1, ITGB1, FN1, MMP9 and STAT1 played different roles in the progression of $C C$ through different signaling pathways. $C D K 1$ and $C C N B 1$ served as regulators of proliferation and differentiation via regulation of the cell cycle and viral tumorigenesis, and initiated CIN and CC, whereas FN1, ITGB1 and $M M P 9$ were co-expressed as a reaction triplet to trigger metastasis via cancer pathways, PI3K-Akt signaling pathway and focal adhesion. FN1 and ITGBI may be novel prognostic factors for CC. STAT1 may have a protective effect in the early stage of HPV infection, but may also act as a proto-oncogene during the invasive stage; however, the specific molecular mechanisms require further investigation.

\section{Acknowledgements}

Not applicable.

\section{Funding}

No funding was received.

\section{Availability of data and materials}

All data generated and/or analyzed during this study are included in this published article. The datasets generated and/or analyzed during the current study are available in the GEO (https://www.ncbi.nlm.nih.gov/geo/) and LinkOmics (http://www.linkedomics.org/) repository.

\section{Authors' contributions}

YY, YF and WZ designed the present study and drafted the initial manuscript. KW and YL performed the literature review, acquired the data and performed the statistical analyses. All authors have read and approved the manuscript.

\section{Ethics approval and consent to participate}

Not applicable.

\section{Patient consent for publication}

Not applicable.

\section{Competing interests}

The authors declare that they have no competing interests.

\section{References}

1. Bray F, Ferlay J, Soerjomataram I, Siegel RL, Torre LA and Jemal A: Global cancer statistics 2018: GLOBOCAN estimates of incidence and mortality worldwide for 36 cancers in 185 countries. CA Cancer J Clin 68: 394-424, 2018.

2. Muliira RS, Salas AS and O'Brien B: Quality of life among female cancer survivors in Africa: An integrative literature review. Asia Pac J Oncol Nurs 4: 6-17, 2017.

3. Gravitt PE and Winer RL: Natural history of HPV infection across the lifespan: Role of viral latency. Viruses 9: E267, 2017.
4. Walboomers JM, Jacobs MV, Manos MM, Bosch FX, Kummer JA, Shah KV, Snijders PJ, Peto J, Meijer CJ and Muñoz N: Human papillomavirus is a necessary cause of invasive cervical cancer worldwide. J Pathol 189: 12-19, 1999.

5. Louie KS, de Sanjose S, Diaz M, Castellsagué X, Herrero R, Meijer CJ, Shah K, Franceschi S, Muñoz N and Bosch FX; International Agency for Research on Cancer Multicenter Cervical Cancer Study Group: Early age at first sexual intercourse and early pregnancy are risk factors for cervical cancer in developing countries. Br J Cancer 100: 1191-1197, 2009.

6. Liu ZC, Liu WD, Liu YH, Ye XH and Chen SD: Multiple sexual partners as a potential independent risk factor for cervical cancer: A meta-analysis of epidemiological studies. Asian Pac J Cancer Prev 16: 3893-3900, 2015

7. Smith JS, Green J, Berrington de Gonzalez A, Appleby P, Peto J, Plummer M, Franceschi S and Beral V: Cervical cancer and use of hormonal contraceptives: A systematic review. Lancet 361: 1159-1167, 2003.

8. Ma YY, Wei SJ, Lin YC, Lung JC, Chang TC, Whang-Peng J, Liu JM, Yang DM, Yang WK and Shen CY: PIK3CA as an oncogene in cervical cancer. Oncogene 19: 2739-2744, 2000.

9. Zheng L, Li T, Zhang Y, Guo Y, Yao J, Dou L and Guo K: Oncogene ATAD2 promotes cell proliferation, invasion and migration in cervical cancer. Oncol Rep 33: 2337-2344, 2015.

10. Bai X, Wang W, Zhao P, Wen J, Guo X, Shen T, Shen J and Yang X: LncRNA CRNDE acts as an oncogene in cervical cancer through sponging miR-183 to regulate CCNB1 expression. Carcinogenesis: Oct 12, 2019 (Epub ahead of print).

11. Bremer GL, Tieboschb AT, van der Putten HW, de Haan J and Arends JW: p53 tumor suppressor gene protein expression in cervical cancer: Relationship to prognosis. Eur J Obstet Gynecol Reprod Biol 63: 55-59, 1995.

12. Cohen Y, Singer G, Lavie O, Dong SM, Beller U and Sidransky D: The RASSF1A tumor suppressor gene is commonly inactivated in adenocarcinoma of the uterine cervix. Clin Cancer Res 9: 2981-2984, 2003.

13. Hasina R, Pontier AL, Fekete MJ, Martin LE, Qi XM, Brigaudeau C, Pramanik R, Cline EI, Coignet LJ and Lingen MW: NOL7 is a nucleolar candidate tumor suppressor gene in cervical cancer that modulates the angiogenic phenotype. Oncogene 25: 588-598, 2006.

14. Roura E, Castellsagué X, Pawlita M, Travier N, Waterboer T, Margall N, Bosch FX, de Sanjosé S, Dillner J, Gram IT, et al: Smoking as a major risk factor for cervical cancer and pre-cancer: Results from the EPIC cohort. Int J cancer 135: 453-466, 2014.

15. Husain RS and Ramakrishnan V: Global variation of human papillomavirus genotypes and selected genes involved in cervical malignancies. Ann Glob Health 81: 675-683, 2015.

16. Soto D, Song C and McLaughlin-Drubin ME: Epigenetic alterations in human papillomavirus-associated cancers. Viruses 9: E248, 2017.

17. Mincheva A, Gissmann L and zur Hausen H: Chromosomal integration sites of human papillomavirus DNA in three cervical cancer cell lines mapped by in situ hybridization. Med Microbiol Immunol 176: 245-256, 1987.

18. Senapati R, Senapati NN and Dwibedi B: Molecular mechanisms of HPV mediated neoplastic progression. Infect Agent Cancer 11: $59,2016$.

19. Münger K, Baldwin A, Edwards KM, Hayakawa H, Nguyen CL, Owens M, Grace M and Huh K: Mechanisms of human papillomavirus-induced oncogenesis. J Virol 78: 11451-11460, 2004.

20. Martinez-Zapien D, Ruiz FX, Poirson J, Mitschler A, Ramirez J, Forster A, Cousido-Siah A, Masson M, Vande Pol S, Podjarny A, et al: Structure of the E6/E6AP/p53 complex required for HPV-mediated degradation of p53. Nature 529: 541-545, 2016.

21. Scheffner M, Huibregtse JM, Vierstra RD and Howley PM: The HPV-16 E6 and E6-AP complex functions as a ubiquitin-protein ligase in the ubiquitination of p53. Cell 75: 495-505, 1993.

22. Sherr CJ: The Pezcoller lecture: Cancer cell cycles revisited. Cancer Res 60: 3689-3695, 2000.

23. Martin LG, Demers GW and Galloway DA: Disruption of the G1/S transition in human papillomavirus type 16 E7-expressing human cells is associated with altered regulation of cyclin $\mathrm{E}$. J Virol 72: 975-985, 1998.

24. Löffler H, Fechter A, Matuszewska M, Saffrich R, Mistrik M, Marhold J, Hornung C, Westermann F, Bartek J and Krämer A: Cep63 recruits $\mathrm{Cdk} 1$ to the centrosome: Implications for regulation of mitotic entry, centrosome amplification, and genome maintenance. Cancer Res 71: 2129-2139, 2011. 
25. Skyldberg B, Fujioka K, Hellström AC, Sylvén L, Moberger B and Auer G: Human papillomavirus infection, centrosome aberration, and genetic stability in cervical lesions. Mod Pathol 14: 279-284, 2001

26. Duensing $\mathrm{S}$ and Münger K: The human papillomavirus type 16 E6 and E7 oncoproteins independently induce numerical and structural chromosome instability. Cancer Res 62: 7075-7082, 2002.

27. Chaiwongkot A, Niruthisard S, Kitkumthorn $\mathrm{N}$ and Bhattarakosol P: Quantitative methylation analysis of human papillomavirus $16 \mathrm{~L} 1$ gene reveals potential biomarker for cervical cancer progression. Diagn Microbiol Infect Dis 89: 265-270, 2017.

28. Sharma A,De R, Javed S, Srinivasan R,Pal A and Bhattacharyya S: Sonic hedgehog pathway activation regulates cervical cancer stem cell characteristics during epithelial to mesenchymal transition. J Cell Physiol: Feb 4, 2019 (Epub ahead of print).

29. Li YP, Zhang L, Zou YL and Yu Y: Association between FGFR4 gene polymorphism and high-risk HPV infection cervical cancer. Asian Pac J Trop Med 10: 680-684, 2017.

30. Zhang J and Gao Y: CCAT-1 promotes proliferation and inhibits apoptosis of cervical cancer cells via the Wnt signaling pathway. Oncotarget 8: 68059-68070, 2017.

31. Mora-García ML, Ávila-Ibarra LR, García-Rocha R, Weiss-Steider B, Hernández-Montes J, Don-López CA, Gutiérrez-Serrano V, Titla-Vilchis IJ, Fuentes-Castañeda MC, Monroy-Mora A, et al: Cervical cancer cells suppress effector functions of cytotoxic T cells through the adenosinergic pathway. Cell Immunol 320: 46-55, 2017.

32. Song ZC, Ding L, Ren ZY, Sun XS, Yang Q, Wang L, Feng MJ, Liu CL and Wang JT: Effects of Src on cervical cancer cells proliferation and apoptosis through ERK signal transduction pathway. Zhonghua Liu Xing Bing Xue Za Zhi 38: 1246-1251, 2017 (In Chinese; Abstract available in Chinese from the publisher).

33. Xu Z, Zhou Y, Shi F, Cao Y, Dinh TLA, Wan J and Zhao M: Investigation of differentially-expressed microRNAs and genes in cervical cancer using an integrated bioinformatics analysis Oncol Lett 13: 2784-2790, 2017.

34. Chen SZ, Ma WL and Zheng WL: Screening for cervical cancer-related genes and their bioinformatics analysis. Nan Fang Yi Ke Da Xue Xue Bao 28: 585-588, 2008 (In Chinese).

35. Nayar R and Wilbur DC: The bethesda system for reporting cervical cytology: A historical perspective. Acta Cytol 61 359-372, 2017

36. Shoji T, Takatori E, Takeuchi S, Yoshizaki A, Uesugi N, Sugai T and Sugiyama T: Clinical significance of atypical glandular cells in the bethesda system 2001: A comparison with the histopathological diagnosis of surgically resected specimens. Cancer Invest 32: 105-109, 2014.

37. O'Connor M, Gallagher P, Waller J, Martin CM, O'Leary JJ and Sharp L; Irish Cervical Screening Research Consortium (CERVIVA): Adverse psychological outcomes following colposcopy and related procedures: A systematic review. BJOG 123 24-38, 2016

38. Haque N, Uddin AFMK, Dey BR, Islam F and Goodman A Challenges to cervical cancer treatment in Bangladesh: The development of a women's cancer ward at Dhaka Medical College Hospital. Gynecol Oncol Rep 21: 67-72, 2017.

39. Roque DR, Wysham WZ and Soper JT: The surgical management of cervical cancer: An overview and literature review. Obstet Gynecol Surv 69: 426-441, 2014.

40. Marin JJ, Romero MR, Blazquez AG, Herraez E, Keck E and Briz O: Importance and limitations of chemotherapy among the available treatments for gastrointestinal tumours. Anticancer Agents Med Chem 9: 162-184, 2009.

41. Chen HHW and Kuo MT: Improving radiotherapy in cancer treatment: Promises and challenges. Oncotarget 8: 62742-62758, 2017

42. Lecavalier-Barsoum M, Chaudary N, Han K, Pintilie M, Hill RP and Milosevic M: Targeting CXCL12/CXCR4 and myeloid cells to improve the therapeutic ratio in patient-derived cervical cancer models treated with radio-chemotherapy. Br J Cancer 121 249-256, 2019

43. Zhang F, Ren CC, Liu L, Chen YN, Yang L, Zhang XA, Wang XM and Yu FJ: SHH gene silencing suppresses epithelial-mesenchymal transition, proliferation, invasion, and migration of cervical cancer cells by repressing the hedgehog signaling pathway. J Cell Biochem 119: 3829-3842, 2018.

44. Gu J, Zhang X, Yang Z and Wang N: Expression of cyclin D1 protein isoforms and its prognostic significance in cervical cancer. Cancer Manag Res 11: 9073-9083, 2019.
45. Chay DB, Han GH, Nam S, Cho H, Chung JY and Hewitt SM: Forkhead box protein O1 (FOXO1) and paired box gene 3 (PAX3) overexpression is associated with poor prognosis in patients with cervical cancer. Int J Clin Oncol 24: 1429-1439, 2019.

46. Tang H, Wang Y, Zhang B, Xiong S, Liu L, Chen W, Tan G and $\mathrm{Li} \mathrm{H}$ : High brain acid soluble protein 1(BASP1) is a poor prognostic factor for cervical cancer and promotes tumor growth. Cancer Cell Int 17: 97, 2017.

47. Yang X, Cheng Y and Li C: The role of TLRs in cervical cancer with HPV infection: A review. Signal Transduct Target Ther 2: $17055,2017$.

48. Frumovitz $\mathrm{M}$ and Sood AK: Vascular endothelial growth factor (VEGF) pathway as a therapeutic target in gynecologic malignancies. Gynecol Oncol 104: 768-778, 2007.

49. den Boon JA, Pyeon D, Wang SS, Horswill M, Schiffman M, Sherman M, Zuna RE, Wang Z, Hewitt SM, Pearson R, et al: Molecular transitions from papillomavirus infection to cervical precancer and cancer: Role of stromal estrogen receptor signaling. Proc Natl Acad Sci USA 112: E3255-E3264, 2015.

50. Barrett T, Wilhite SE, Ledoux P, Evangelista C, Kim IF, Tomashevsky M, Marshall KA, Phillippy KH, Sherman PM, Holko M, et al: NCBI GEO: Archive for functional genomics data sets-update. Nucleic Acids Res 41: D991-D995, 2013.

51. Ritchie ME, Phipson B, Wu D, Hu Y,Law CW, Shi W and Smyth GK: Limma powers differential expression analyses for RNA-sequencing and microarray studies. Nucleic Acids Res 43: e47, 2015.

52. Szklarczyk D, Franceschini A, Wyder S, Forslund K, Heller D, Huerta-Cepas J, Simonovic M, Roth A, Santos A, Tsafou KP, et al: STRING v10: Protein-protein interaction networks, integrated over the tree of life. Nucleic Acids Res 43: D447-D452, 2015.

53. Shannon P, Markiel A, Ozier O, Baliga NS, Wang JT, Ramage D, Amin N, Schwikowski B and Ideker T: Cytoscape: A software environment for integrated models of biomolecular interaction networks. Genome Res 13: 2498-2504, 2003.

54. Chin $\mathrm{CH}$, Chen $\mathrm{SH}$, Wu HH, Ho CW, Ko MT and Lin CY: cytoHubba: Identifying hub objects and sub-networks from complex interactome. BMC Syst Biol 8 (Suppl 4): S11, 2014.

55. Wang J, Vasaikar S, Shi Z, Greer $M$ and Zhang B WebGestalt 2017: A more comprehensive, powerful, flexible and interactive gene set enrichment analysis toolkit. Nucleic Acids Res 45: W130-W137, 2017.

56. Chen J, Bardes EE, Aronow BJ and Jegga AG: ToppGene Suite for gene list enrichment analysis and candidate gene prioritization. Nucleic Acids Res 37: W305-W311, 2009.

57. Hu Y, Pan Z, Hu Y, Zhang L and Wang J: Network and pathway-based analyses of genes associated with Parkinson's disease. Mol Neurobiol 54: 4452-4465, 2017.

58. Scardoni G, Petterlini M and Laudanna C: Analyzing biological network parameters with CentiScaPe. Bioinformatics 25: 2857-2859, 2009.

59. Han JD, Berlin N, Hao T, Goldberg DS, Berriz GF, Zhang LV, Dupuy D, Walhout AJ, Cusick ME, Roth FP and Vidal M: Evidence for dynamically organized modularity in the yeast protein-protein interaction network. Nature 430: 88-93, 2004.

60. Kanwal A and Fazal S: Construction and analysis of protein-protein interaction network correlated with ankylosing spondylitis. Gene 638: 41-51, 2018

61. Wu J, Vallenius T, Ovaska K, Westermarck J, Mäkelä TP and Hautaniemi S: Integrated network analysis platform for protein-protein interactions. Nat Methods 6: 75-77, 2009.

62. Kerrien S, Alam-Faruque Y, Aranda B, Bancarz I, Bridge A, Derow C, Dimmer E, Feuermann M, Friedrichsen A, Huntley R, et al: IntAct-source resource for molecular interaction data. Nucleic Acids Res 35: D561-D565, 2007.

63. Chatr-aryamontri A, Ceol A, Palazzi LM, Nardelli G, Schneider MV, Castagnoli L and Cesareni G: MINT: The Molecular INTeraction database. Nucleic Acids Res 35: D572-D574, 2007.

64. Breitkreutz BJ, Stark C, Reguly T, Boucher L, Breitkreutz A, Livstone M, Oughtred R, Lackner DH, Bähler J, Wood V, et al: The BioGRID interaction database: 2008 update. Nucleic Acids Res 36: D637-D640, 2008.

65. Salwinski L, Miller CS, Smith AJ, Pettit FK, Bowie JU and Eisenberg D: The database of interacting proteins: 2004 update. Nucleic Acids Res 32: D449-D451, 2004.

66. Peri S, Navarro JD, Amanchy R, Kristiansen TZ, Jonnalagadda CK, Surendranath V, Niranjan V, Muthusamy B, Gandhi TK, Gronborg M, et al: Development of human protein reference database as an initial platform for approaching systems biology in humans. Genome Res 13: 2363-2371, 2003. 
67. Güldener U, Münsterkötter M, Oesterheld M, Pagel P, Ruepp A Mewes HW and Stümpflen V: MPact: The MIPS protein interaction resource on yeast. Nucleic Acids Res 34: D436-D441, 2006.

68. Vasaikar SV, Straub P, Wang J and Zhang B: LinkedOmics: Analyzing multi-omics data within and across 32 cancer types. Nucleic Acids Res 46: D956-D963, 2018.

69. Cancer Genome Atlas Research Network, Weinstein JN, Collisson EA, Mills GB, Shaw KR, Ozenberger BA, Ellrott K, Shmulevich I, Sander C and Stuart JM: The cancer genome atlas pan-cancer analysis project. Nat Genet 45: 1113-1120, 2013.

70. Gasca S, Pellestor F, Assou S, Loup V, Anahory T, Dechaud H, De Vos $\mathbf{J}$ and Hamamah S: Identifying new human oocyte marker genes: A microarray approach. Reprod Biomed Online 14: 175-183, 2007.

71. Schwab MS, Roberts BT, Gross SD, Tunquist BJ, Taieb FE, Lewellyn AL and Maller JL: Bub1 is activated by the protein kinase p90(Rsk) during Xenopus oocyte maturation. Curr Biol 11: 141-150, 2001.

72. Ouandaogo ZG, Frydman N, Hesters L, Assou S, Haouzi D, Dechaud H, Frydman R and Hamamah S: Differences in transcriptomic profiles of human cumulus cells isolated from oocytes at GV, MI and MII stages after in vivo and in vitro oocyte maturation. Hum Reprod 27: 2438-2447, 2012.

73. Li J, Qian WP and Sun QY: Cyclins regulating oocyte meiotic cell cycle progression†. Biol Reprod 101: 878-881, 2019.

74. Kaplan MH: STAT signaling in inflammation. JAKSTAT 2: e24198, 2013.

75. Qiu X, Guo H, Yang J, Ji Y, Wu CS and Chen X: Down-regulation of guanylate binding protein 1 causes mitochondrial dysfunction and cellular senescence in macrophages. Sci Rep 8: 1679, 2018.

76. Bros M, Haas K, Moll L and Grabbe S: RhoA as a key regulator of innate and adaptive immunity. Cells 8: E733, 2019.

77. Erdely A,Antonini JM,Salmen-Muniz R,Liston A,Hulderman T, Simeonova PP, Kashon ML, Li S, Gu JK, Stone S, et al: Type I interferon and pattern recognition receptor signaling following particulate matter inhalation. Part Fibre Toxicol 9: 25, 2012.

78. Luu K, Greenhill CJ, Majoros A, Decker T, Jenkins BJ and Mansell A: STAT1 plays a role in TLR signal transduction and inflammatory responses. Immunol Cell Biol 92: 761-769, 2014.

79. Smolen KK, Ruck CE, Fortuno ES III, Ho K, Dimitriu P, Mohn WW, Speert DP, Cooper PJ, Esser M, Goetghebuer T, et al: Pattern recognition receptor-mediated cytokine response in infants across 4 continents. J Allergy Clin Immunol 133 818-826.e4, 2014

80. Xiang C, Chen J and Fu P: HGF/Met signaling in cancer invasion: The impact on cytoskeleton remodeling. Cancers (Basel) 9: E44, 2017

81. Lei T and Ling X: IGF-1 promotes the growth and metastasis of hepatocellular carcinoma via the inhibition of proteasome-mediated cathepsin B degradation. World J Gastroenterol 21: 10137-10149, 2015.

82. Cho S, Kitadai Y, Yoshida S, Tanaka S, Yoshihara M, Yoshida K and Chayama K: Deletion of the KIT gene is associated with liver metastasis and poor prognosis in patients with gastrointestina stromal tumor in the stomach. Int J Oncol 28: 1361-1367, 2006.

83. Li B, Shen W, Peng H, Li Y, Chen F, Zheng L, Xu J and Jia L: Fibronectin 1 promotes melanoma proliferation and metastasis by inhibiting apoptosis and regulating EMT. Onco Targets Ther 12: 3207-3221, 2019.

84.Liu Y, Ren CC, Yang L, Xu YM and Chen YN: Role of CXCL12-CXCR4 axis in ovarian cancer metastasis and CXCL12-CXCR4 blockade with AMD3100 suppresses tumor cell migration and invasion in vitro. J Cell Physiol 234 3897-3909, 2019.

85. Chen Y, Jiang J, Zhao M, Luo X, Liang Z, Zhen Y, Fu Q, Deng $\mathrm{X}$, Lin X, Li L, et al: microRNA-374a suppresses colon cancer progression by directly reducing CCND1 to inactivate the PI3K/AKT pathway. Oncotarget 7: 41306-41319, 2016.

86. Thomas SJ, Snowden JA, Zeidler MP and Danson SJ: The role of JAK/STAT signalling in the pathogenesis, prognosis and treatment of solid tumours. Br J Cancer 113: 365-371, 2015.

87. Stacker SA and Achen MG: The VEGF signaling pathway in cancer: The road ahead. Chin J Cancer 32: 297-302, 2013.

88. Shi X, Wang J, Lei Y, Cong C, Tan D and Zhou X: Research progress on the PI3K/AKT signaling pathway in gynecological cancer (Review). Mol Med Rep 19: 4529-4535, 2019.

89. Li X, Jiang S and Tapping RI: Toll-like receptor signaling in cell proliferation and survival. Cytokine 49: 1-9, 2010.

90. Gene Ontology Consortium: Gene ontology consortium: Going forward. Nucleic Acids Res 43: D1049-D1056, 2015.
91. Kawai T and Akira S: Toll-like receptor and RIG-1-like receptor signaling. Ann N Y Acad Sci 1143: 1-20, 2008.

92. Gkretsi V and Stylianopoulos T: Cell adhesion and matrix stiffness: Coordinating cancer cell invasion and metastasis. Front Oncol 8: 145, 2018.

93. Zhang YL, Wang RC, Cheng K, Ring BZ and Su L: Roles of Rap1 signaling in tumor cell migration and invasion. Cancer Biol Med 14: 90-99, 2017.

94. Campbell PM and Der CJ: Oncogenic Ras and its role in tumor cell invasion and metastasis. Semin Cancer Biol 14: 105-114, 2004.

95. Sun F, Wang J, Sun Q, Li F, Gao H, Xu L, Zhang J, Sun X, Tian Y, Zhao $\mathrm{Q}$, et al: Interleukin-8 promotes integrin $\beta 3$ upregulation and cell invasion through PI3K/Akt pathway in hepatocellular carcinoma. J Exp Clin Cancer Res 38: 449, 2019.

96. Sanderson RD: Heparan sulfate proteoglycans in invasion and metastasis. Semin Cell Dev Biol 12: 89-98, 2001.

97. Loo YM and Gale M Jr: Immune signaling by RIG-I-like receptors. Immunity 34: 680-692, 2011

98. Nyati KK and Prasad KN: Role of cytokines and Toll-like receptors in the immunopathogenesis of Guillain-Barré syndrome. Mediators Inflamm 2014: 758639, 2014

99. Saxena M and Yeretssian G: NOD-Like receptors: Master regulators of inflammation and cancer. Front Immunol 5: 327, 2014.

100. Crosbie EJ, Einstein MH, Franceschi S and Kitchener HC: Human papillomavirus and cervical cancer. Lancet 382: 889-899, 2013

101. Balasubramaniam SD, Balakrishnan V, Oon CE and Kaur G: Key molecular events in cervical cancer development. Medicina (Kaunas) 55: E384, 2019.

102. Lin M, Ye M, Zhou J, Wang ZP and Zhu X: Recent advances on the molecular mechanism of cervical carcinogenesis based on systems biology technologies. Comput Struct Biotechnol J 17: 241-250, 2019.

103. Ye J, Yin L, Xie P, Wu J, Huang J, Zhou G, Xu H, Lu E and He X: Antiproliferative effects and molecular mechanisms of troglitazone in human cervical cancer in vitro. Onco Targets Ther 8: 1211-1218, 2015.

104. Yugawa T and Kiyono T: Molecular mechanisms of cervical carcinogenesis by high-risk human papillomaviruses: Novel functions of E6 and E7 oncoproteins. Rev Med Virol 19: 97-113, 2009.

105. Jones MC, Askari JA, Humphries JD and Humphries MJ: Cell adhesion is regulated by CDK1 during the cell cycle. J Cell Biol 217: 3203-3218, 2018.

106. Hochegger H, Dejsuphong D, Sonoda E, Saberi A, Rajendra E, Kirk J, Hunt T and Takeda S: An essential role for Cdk1 in S phase control is revealed via chemical genetics in vertebrate cells. J Cell Biol 178: 257-268, 2007.

107. Vassilev LT: Cell cycle synchronization at the G2/M phase border by reversible inhibition of CDK1. Cell Cycle 5: 2555-2556, 2006

108. Shaikh F, Sanehi P and Rawal R: Molecular screening of compounds to the predicted protein-protein interaction site of Rb1-E7 with p53-E6 in HPV. Bioinformation 8: 607-612, 2012.

109. Yun J, Chae HD, Choy HE, Chung J, Yoo HS, Han MH and Shin DY: p53 negatively regulates cdc2 transcription via the CCAAT-binding NF-Y transcription factor. J Biol Chem 274 29677-29682, 1999.

110. Lindqvist A, van Zon W, Karlsson Rosenthal C and Wolthuis RM: Cyclin B1-Cdk1 activation continues after centrosome separation to control mitotic progression. PLoS Biol 5: e123, 2007.

111. Crasta K, Huang P, Morgan G, Winey M and Surana U: Cdk1 regulates centrosome separation by restraining proteolysis of microtubule-associated proteins. EMBO J 25: 2551-2563, 2006

112. Fang Y, Yu H, Liang X, Xu J and Cai X: Chk1-induced CCNB1 overexpression promotes cell proliferation and tumor growth in human colorectal cancer. Cancer Biol Ther 15: 1268-1279, 2014

113. Krek W and Nigg EA: Differential phosphorylation of vertebrate $\mathrm{p} 34 \mathrm{cdc} 2$ kinase at the G1/S and G2/M transitions of the cell cycle: Identification of major phosphorylation sites. EMBO J 10: 305-316, 1991.

114. Morgan DO: Principles of CDK regulation. Nature 374: 131-134, 1995.

115. Banerjee NS, Wang HK, Broker TR and Chow LT: Human papillomavirus (HPV) E7 induces prolonged G2 following $S$ phase reentry in differentiated human keratinocytes. J Biol Chem 286: 15473-15482, 2011. 
116. Morgan EL, Wasson CW, Hanson L, Kealy D, Pentland I, McGuire V, Scarpini C, Coleman N, Arthur JSC, Parish JL, et al: STAT3 activation by E6 is essential for the differentiation-dependent HPV18 life cycle. PLoS Pathog 14: e1006975, 2018.

117. Stewart DA, Cooper CR and Sikes RA: Changes in extracellular matrix (ECM) and ECM-associated proteins in the metastatic progression of prostate cancer. Reprod Biol Endocrinol 2: 2, 2004.

118. Chiu CF, Ho MY, Peng JM, Hung SW, Lee WH, Liang CM and Liang SM: Raf activation by Ras and promotion of cellular metastasis require phosphorylation of prohibitin in the raft domain of the plasma membrane. Oncogene 32: 777-787, 2013.

119. Matter ML and Ruoslahti E: A signaling pathway from the alpha5beta1 and alpha(v)beta3 integrins that elevates bcl-2 transcription. J Biol Chem 276: 27757-27763, 2001.

120. Egeblad $\mathrm{M}$ and Werb Z: New functions for the matrix metalloproteinases in cancer progression. Nat Rev Cancer 2: 161-174, 2002.

121. Sand JM, Larsen L, Hogaboam C, Martinez F, Han M, Røssel Larsen M, Nawrocki A, Zheng Q, Karsdal MA and Leeming DJ: MMP mediated degradation of type IV collagen alpha 1 and alpha 3 chains reflects basement membrane remodeling in experimental and clinical fibrosis-validation of two novel biomarker assays. PLoS One 8: e84934, 2013.

122. Bokhari AA, Baker TM, Dorjbal B, Waheed S, Zahn CM, Hamilton CA, Maxwell GL and Syed V: Nestin suppression attenuates invasive potential of endometrial cancer cells by downregulating TGF- $\beta$ signaling pathway. Oncotarget 7: 69733-69748, 2016

123. da Silva Cardeal LB, Brohem CA, Corrêa TC, Winnischofer SM, Nakano F, Boccardo E, Villa LL, Sogayar MC and Maria-Engler SS: Higher expression and activity of metalloproteinases in human cervical carcinoma cell lines is associated with HPV presence. Biochem Cell Biol 84: 713-719, 2006.

124. Cardeal LB, Boccardo E, Termini L, Rabachini T, Andreoli MA di Loreto C, Longatto Filho A, Villa LL and Maria-Engler SS: HPV16 oncoproteins induce MMPs/RECK-TIMP-2 imbalance in primary keratinocytes: Possible implications in cervical carcinogenesis. PLoS One 7: e33585, 2012.
125. Shiau MY, Fan LC, Yang SC, Tsao CH, Lee H, Cheng YW, Lai LC and Chang YH: Human papillomavirus up-regulates MMP-2 and MMP-9 expression and activity by inducing interleukin-8 in lung adenocarcinomas. PLoS One 8: e54423, 2013.

126. Ding Y, Pan Y, Liu S, Jiang F and Jiao J: Elevation of MiR-9-3p suppresses the epithelial-mesenchymal transition of nasopharyngeal carcinoma cells via down-regulating FN1, ITGB1 and ITGAV. Cancer Biol Ther 18: 414-424, 2017.

127. Wang J, Deng L, Huang J, Cai R, Zhu X, Liu F, Wang Q, Zhang J and Zheng Y: High expression of Fibronectin 1 suppresses apoptosis through the NF- $\kappa \mathrm{B}$ pathway and is associated with migration in nasopharyngeal carcinoma. Am J Transl Res 9: 4502-4511, 2017.

128. Rajkumar T, Sabitha K, Vijayalakshmi N, Shirley S, Bose MV, Gopal $\mathrm{G}$ and Selvaluxmy G: Identification and validation of genes involved in cervical tumourigenesis. BMC Cancer 11: 80, 2011.

129. Koromilas AE and Sexl V: The tumor suppressor function of STAT1 in breast cancer. JAKSTAT 2: e23353, 2013.

130. Zhang Y and Liu Z: STAT1 in cancer: Friend or foe? Discov Med 24: 19-29, 2017.

131. Akram M, Kim KA, Kim ES, Shin YJ, Noh D, Kim E, Kim JH, Majid A, Chang SY, Kim JK and Bae ON: Selective inhibition of JAK2/STAT1 signaling and iNOS expression mediates the anti-inflammatory effects of coniferyl aldehyde. Chem Biol Interact 256: 102-110, 2016.

This work is licensed under a Creative Commons Attribution-NonCommercial-NoDerivatives 4.0 International (CC BY-NC-ND 4.0) License. 